University of Nebraska - Lincoln

DigitalCommons@University of Nebraska - Lincoln

Publications, Agencies and Staff of the U.S.

Department of Commerce

U.S. Department of Commerce

2010

\title{
Long-term recovery patterns of arctic tundra after winter seismic exploration
}

Janet C. Jorgenson

Arctic National Wildlife Refuge, U.S. Fish and Wildlife Service

Jay M. Ver Hoef

NOAA National Marine Mammal Lab, Alaska Fisheries Science Center, National Marine Fisheries Service

M. T. Jorgenson

Alaska Ecoscience

Follow this and additional works at: https://digitalcommons.unl.edu/usdeptcommercepub

Part of the Environmental Sciences Commons

Jorgenson, Janet C.; Ver Hoef, Jay M.; and Jorgenson, M. T., "Long-term recovery patterns of arctic tundra after winter seismic exploration" (2010). Publications, Agencies and Staff of the U.S. Department of Commerce. 187.

https://digitalcommons.unl.edu/usdeptcommercepub/187

This Article is brought to you for free and open access by the U.S. Department of Commerce at DigitalCommons@University of Nebraska - Lincoln. It has been accepted for inclusion in Publications, Agencies and Staff of the U.S. Department of Commerce by an authorized administrator of DigitalCommons@University of Nebraska - Lincoln. 


\title{
Long-term recovery patterns of arctic tundra after winter seismic exploration
}

\author{
Janet C. Jorgenson, ${ }^{1,4} \mathrm{~J}_{\text {Ay }}$ M. Ver Hoef, ${ }^{2}$ AND M. T. Jorgenson ${ }^{3}$ \\ ${ }^{1}$ Arctic National Wildlife Refuge, U.S. Fish and Wildlife Service, 101 12th Avenue, Room 236, Fairbanks, Alaska 99701 USA \\ ${ }^{2}$ NOAA National Marine Mammal Lab, Alaska Fisheries Science Center, National Marine Fisheries Service, \\ Seattle, Washington 98115 USA \\ ${ }^{3}$ Alaska Ecoscience, 2332 Cordes Way, Fairbanks, Alaska 99709 USA
}

\begin{abstract}
In response to the increasing global demand for energy, oil exploration and development are expanding into frontier areas of the Arctic, where slow-growing tundra vegetation and the underlying permafrost soils are very sensitive to disturbance. The creation of vehicle trails on the tundra from seismic exploration for oil has accelerated in the past decade, and the cumulative impact represents a geographic footprint that covers a greater extent of Alaska's North Slope tundra than all other direct human impacts combined. Seismic exploration for oil and gas was conducted on the coastal plain of the Arctic National Wildlife Refuge, Alaska, USA, in the winters of 1984 and 1985. This study documents recovery of vegetation and permafrost soils over a two-decade period after vehicle traffic on snow-covered tundra. Paired permanent vegetation plots (disturbed vs. reference) were monitored six times from 1984 to 2002. Data were collected on percent vegetative cover by plant species and on soil and ground ice characteristics. We developed Bayesian hierarchical models, with temporally and spatially autocorrelated errors, to analyze the effects of vegetation type and initial disturbance levels on recovery patterns of the different plant growth forms as well as soil thaw depth. Plant community composition was altered on the trails by species-specific responses to initial disturbance and subsequent changes in substrate. Long-term changes included increased cover of graminoids and decreased cover of evergreen shrubs and mosses. Trails with low levels of initial disturbance usually improved well over time, whereas those with medium to high levels of initial disturbance recovered slowly. Trails on ice-poor, gravel substrates of riparian areas recovered better than those on ice-rich loamy soils of the uplands, even after severe initial damage. Recovery to pre-disturbance communities was not possible where trail subsidence occurred due to thawing of ground ice. Previous studies of disturbance from winter seismic vehicles in the Arctic predicted short-term and mostly aesthetic impacts, but we found that severe impacts to tundra vegetation persisted for two decades after disturbance under some conditions. We recommend management approaches that should be used to prevent persistent tundra damage.
\end{abstract}

Key words: Arctic National Wildlife Refuge, Alaska, USA; arctic tundra; induced thawing; long-term damage; permafrost soils; plant community; recovery; seismic exploration; thermokarst; winter trail disturbance.

\section{INTRODUCTION}

In response to the increasing global demand for energy, oil exploration and development are expanding into frontier areas of the Arctic, where slow-growing tundra vegetation and the underlying permafrost soils are very sensitive to disturbance (NRC 2003). This expanding human activity is occurring with insufficient knowledge of the long-term impacts to arctic ecosystems and there is an urgent need to improve the management of oil exploration and development across diverse ecosystems. In this paper, we provide results from long-term monitoring of disturbance associated with oil exploration in northern Alaska that we hope will

Manuscript received 6 October 2008; revised 10 March 2009; accepted 30 March 2009. Corresponding Editor: J. Belnap.

${ }^{4}$ E-mail: janet_jorgenson@fws.gov contribute to reducing impacts of industrial activity in the Arctic.

Early oil exploration in northern Alaska in the 1940s, during an era of minimal environmental concern, created numerous scars that are still visible 60 years later. This long-term damage was primarily a consequence of severe surface disturbance that induced thawing of permafrost (Lawson 1986). Since about 1970, however, impacts have been substantially reduced by conducting exploration during winter when the ground is frozen and snow covered (Hernandez 1973, Walker et al. 1987). Seismic exploration for oil requires multiple vehicles to travel on surveyed grids over the tundra. Short-term studies of these winter vehicle trails (2-8 years) found disturbance was greatly reduced by land-management regulations and the studies typically predicted that winter trails would recover fully within a 


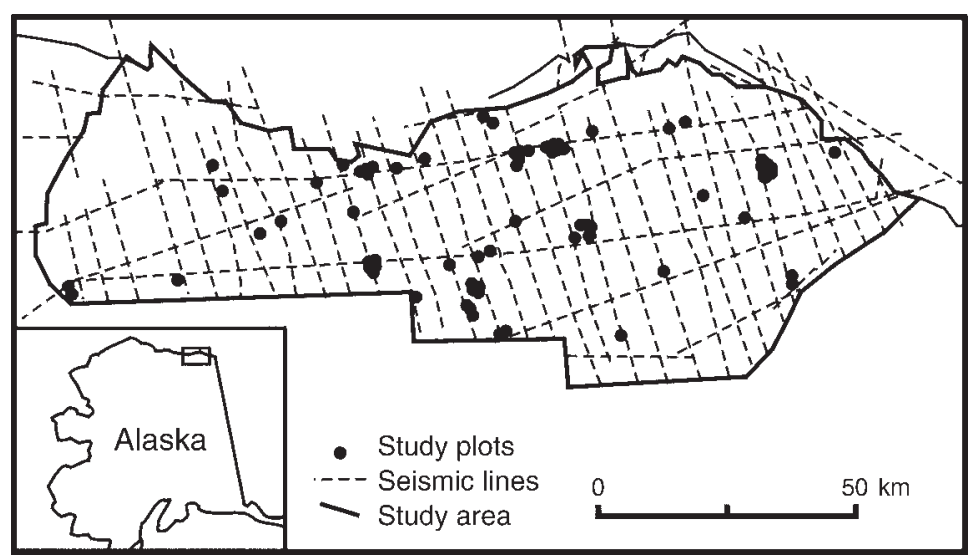

FIG. 1. Map of 1984-1985 seismic lines and study plots in Arctic National Wildlife Refuge (ANWR), Alaska, USA. Plots (paired disturbed-reference) are located on seismic lines (shown) and on adjacent camp-move trails (not shown).

decade (Bliss and Wein 1972, Chapin and Shaver 1981, Reynolds 1982, Densmore 1985, Walker et al. 1987). Accordingly, the oil industry and government regulators generally consider winter seismic exploration to be a low-impact activity with only short-term aesthetic impacts (NRC 2003).

The creation of seismic trails has accelerated in the past decade, however, and the cumulative impact represents a geographic footprint that covers a greater extent of Alaska's North Slope tundra than all other direct human impacts combined (NRC 2003). Despite the magnitude of this activity, there is insufficient information on the long-term impacts of winter seismic exploration on tundra to effectively manage this rapidly expanding exploration activity and to accurately estimate the overall amount of human disturbance in the Arctic. We address this data gap by continuing to monitor the recovery of tundra vegetation and soil that was disturbed by winter seismic exploration in 1984 and 1985 on the coastal plain of the Arctic National Wildlife Refuge (Arctic NWR), Alaska. Earlier papers documented recovery on trails during the first seven years of this study (Felix and Raynolds 1989a, b, Raynolds and Felix 1989, Felix et al. 1992, Emers et al. 1995, Emers and Jorgenson 1997). This paper documents recovery after 18 years.

Of particular concern for off-road tundra travel is the sensitivity of permafrost to disturbance because degradation and thaw settlement can lead to dramatic shifts in recovery patterns away from original conditions, depending on ice contents of the permafrost. This concern is exacerbated by recent climate warming that has made ground ice more susceptible to thaw (Jorgenson et al. 2006). A warming climate also is likely to alter the competitive interactions between different plant species as they revegetate bare ground on trails. Thus, it is imperative to document recovery patterns over the last two decades to better understand how disturbance and recovery patterns may change in a warming Arctic.
Evaluating disturbance and recovery is difficult due to the complex interactions among disturbance characteristics (e.g., vehicle type, number of passes), the factors that affect resistance to disturbance (e.g., vegetation, soil, snow, surface hydrology, permafrost, topography), and varying response of ecosystem components (e.g., grasses vs. evergreen shrubs). Spatial variability of these factors rarely can be controlled to provide an optimal statistical design for analyzing the patterns across a range of conditions (Ver Hoef 2002). Sample sizes can be highly variable across all combinations of disturbance levels and terrain conditions. To address these problems in analyzing post hoc disturbance data, we developed a new Bayesian hierarchical modeling approach to better estimate the effects of intensity of initial disturbance, plant growth form, vegetation type, and time to recovery.

Objectives of this study were to: (1) quantify changes in plant cover and soil thaw depth over an 18-year period after disturbance; (2) determine long-term recovery patterns by comparing the responses of differing plant growth forms and plant communities to varying levels of initial disturbance; (3) compare our results to predictions from earlier reports and other studies; and (4) develop recommendations for land management that can help to reduce long-term impacts.

\section{Methods \\ Study area}

The study area is on the coastal plain of the Arctic National Wildlife Refuge (ANWR) in northeastern Alaska, between $69^{\circ} 30^{\prime} \mathrm{N}$ and $70^{\circ} 10^{\prime} \mathrm{N}$ (Fig. 1). It lies within low-arctic tundra and is bordered by the Brooks Range to the south and the Beaufort Sea to the north. It has low precipitation, very low winter temperatures, and short, cool summers. Soils are underlain by continuous permafrost, and the thawed surface layer reaches an average maximum depth of $15-60 \mathrm{~cm}$ in August. The ground surface remains frozen and snow covered from 
TABLE 1. Vegetation types of the coastal plain of the Arctic NWR, Alaska, USA, based on Walker et al. (1982).

\begin{tabular}{|c|c|}
\hline Type & Description \\
\hline Wet sedge tundra ( $13 \%$ of area) & $\begin{array}{l}\text { Low-lying flats and drainages with the sedges Carex aquatilis and Eriophorum angustifolium } \\
\text { and little moss or shrub cover. The poorly drained soils are saturated throughout the } \\
\text { summer and have a thick, fibrous organic horizon. }\end{array}$ \\
\hline Sedge-willow tundra $(30 \%)$ & $\begin{array}{l}\text { Low-lying flats and gentle slopes with the sedges Eriophorum angustifolium and Carex } \\
\text { aquatilis and the willows Salix pulchra and } S \text {. reticulata. Mosses include Tomenthypnum } \\
\text { nitens, Hylocomium splendens, Aulacomnium spp., Sphagnum spp., and Campylium } \\
\text { stellatum. On fine-grained retransported, glaciofluvial, and abandoned floodplain deposits. } \\
\text { Soils have moderately thick organic layer and are saturated at intermediate depths but } \\
\text { generally free of surface water. }\end{array}$ \\
\hline Sedge-Dryas tundra (13\%) & $\begin{array}{l}\text { Moderately well-drained sites dominated by the dwarf shrub Dryas integrifolia and the } \\
\text { sedge Carex bigelowii, with the willows Salix richardsonii, S. phlebophylla, and S. } \\
\text { reticulata and mosses such as Tomenthypnum nitens, Hylocomium splendens, Distichium } \\
\text { capillaceum, and Ditrichum flexicaule. Forbs (e.g., Lupinus arcticus), lichens (e.g., Cetraria } \\
\text { spp.), and horsetails (e.g., Equisetum variegatum) are common. Found on moist } \\
\text { calcareous slopes and pebbly glacial and marine sediments. Notable for a hummocky } \\
\text { surface topography, patches of exposed mineral soil, and extremely variable organic } \\
\text { horizons resulting from active and stabilized frost boils. }\end{array}$ \\
\hline Tussock tundra $(28 \%)$ & $\begin{array}{l}\text { Moderately well-drained slopes dominated by the tussock-forming sedge Eriophorum } \\
\text { vaginatum, with shrubs Salix pulchra, Betula nana, Ledum palustre ssp. decumbens, and } \\
\text { Vaccinium vitis-idaea. Bryophytes include Hylocomium splendens, Sphagnum spp., } \\
\text { Aulacomnium turgidum, Ptilidium ciliare, and Tomenthypnum nitens. Occurs on deposits of } \\
\text { loess or colluvial material on top of coarser, residual materials or glacial drift. }\end{array}$ \\
\hline Shrub tundra $(5 \%)$ & $\begin{array}{l}\text { Dominated by low and dwarf shrubs, with Betula nana or Salix pulchra and understory } \\
\text { species similar to tussock tundra. In the study area, occurs only on raised areas with } \\
\text { high-centered polygon surface morphology. }\end{array}$ \\
\hline Riparian shrubland (2\%) & $\begin{array}{l}\text { Willow shrublands on river floodplains and stream banks, dominated by Salix alaxensis, } S \text {. } \\
\text { glauca, and } S \text {. richardsonii, commonly with a forb understory. Willows have an average } \\
\text { height of } 0.5 \mathrm{~m} \text { and maximum of about } 1.5 \mathrm{~m} \text {. Occurs on both young floodplain deposits } \\
\text { with mixed gravel and fine-grained material, and older terraces with a thin, fine-grained } \\
\text { alluvium layer over gravel. }\end{array}$ \\
\hline Dryas terrace $(3 \%)$ & $\begin{array}{l}\text { Infrequently flooded river terraces with Dryas integrifolia and other dwarf shrubs, forbs, } \\
\text { horsetails, mosses, and lichens similar to sedge-Dryas tundra. Well-drained soils with a } \\
\text { very thin organic mat over river deposits. }\end{array}$ \\
\hline
\end{tabular}

approximately mid-September to early June. Winter snow cover is shallow due to low precipitation and variable because of redistribution by high winds, resulting in sparse cover on hillcrests and deep accumulations in water courses.

Foothills of the Brooks Range cover $45 \%$ of the area (Walker et al. 1982). Broad uplands are dissected by north-flowing rivers. Hilly coastal plains cover $22 \%$ of the area and have gently undulating tundra with small thaw lakes. Flat thaw lake plains with large lakes cover $3 \%$ of the area. River floodplains cover $25 \%$ of the area. Vegetation is a nearly continuous, highly interspersed mosaic of plants less than $0.5 \mathrm{~m}$ tall, mainly sedges, low shrubs, and mosses. Shrubs are taller along drainages. Soil texture and moisture are important determinants of the different tundra vegetation types (Table 1), which were based on Walker et al. (1982).

\section{Description of seismic exploration activities}

Seismic exploration maps subsurface geological structures by sending shock waves into the ground from surface vehicles and recording their reflectance patterns. Vehicles travel along a surveyed grid, with multiple vehicle passes along each line. Approximately $2000 \mathrm{~km}$ of seismic exploration line were completed in a $5 \times 10$ $\mathrm{km}$ grid over a $6300 \mathrm{~km}^{2}$ area (Fig. 1). Over $2000 \mathrm{~km}$ of additional trails were created adjacent to the seismic lines by D-7 Caterpillar tractors pulling ski-mounted trailers (cat-trains) between crew camps. Trail widths ranged from $4 \mathrm{~m}$ to $>50 \mathrm{~m}$. Exploration occurred from January through May, 1984 and 1985, when requirements were met for minimum protective snow cover (15 $\mathrm{cm})$ and depth of frozen soil surface $(30 \mathrm{~cm})$. The U.S. Fish and Wildlife Service enforced permit stipulations to minimize impacts to vegetation and wildlife. Monitors traveled with the seismic crews to choose routes that avoided the most easily damaged areas, such as steep slopes and snow-free areas. Seismic vehicles included vibrator units $(4.5 \mathrm{psi}[=31.0 \mathrm{kPa}])$ and dynamite units (2.8 psi $[=17.2 \mathrm{kPa}])$, plus smaller personnel carriers. The highest ground pressure vehicles were D-7 caterpillar tractors $(10.5$ psi $[=72.4 \mathrm{kPa}])$.

\section{Field sampling}

Thirty permanent paired plots (disturbed, reference) were established along new vehicle trails in 1984 and 1985. Disturbed plots were chosen from across the study area to represent different vegetation types at low, medium, and high levels of initial disturbance. Reference plots were established 2-10 $\mathrm{m}$ away from disturbed plots on undisturbed tundra with the same topography and vegetation. Plots were observed the first two summers after disturbance (1984 and 1985, or 1985 and 1986) and in 1988,1991 , and 2002. 
TABLE 2. Disturbance rating scheme for winter seismic trails on the coastal plain of the Arctic NWR, Alaska, adapted from Radforth (1972).

\begin{tabular}{|c|c|}
\hline $\begin{array}{l}\text { Factor } \\
\text { and level }\end{array}$ & Description \\
\hline \multicolumn{2}{|c|}{ Decrease in percent cover of plants } \\
\hline 0 & no observable change \\
\hline 1 & $0-25 \%$ change \\
\hline 2 & $25-50 \%$ change \\
\hline 3 & over $50 \%$ change \\
\hline \multicolumn{2}{|c|}{ Decrease in percent cover of shrub canopy } \\
\hline 0 & no observable change \\
\hline 1 & $0-25 \%$ change \\
\hline 2 & $25-50 \%$ change \\
\hline 3 & over $50 \%$ change \\
\hline \multicolumn{2}{|c|}{ Change in percentage of organic or mineral soil exposed } \\
\hline 0 & none observed \\
\hline 1 & $1-5 \%$ change \\
\hline 2 & $5-15 \%$ change \\
\hline 3 & over $15 \%$ change \\
\hline \multicolumn{2}{|c|}{ Damage to microscale structure } \\
\hline 0 & scattered scuffing of tussocks or hummocks \\
\hline 1 & $\begin{array}{l}\text { most tussocks or hummocks scuffed, some } \\
\text { crushed }\end{array}$ \\
\hline 2 & most tussocks or hummocks crushed \\
\hline 3 & $\begin{array}{l}\text { ruts or crushed tussocks and hummocks } \\
\text { nearly continuous }\end{array}$ \\
\hline \multicolumn{2}{|c|}{ Trail subsidence or compression } \\
\hline 0 & no observable compression \\
\hline 1 & $\begin{array}{l}\text { slight compression of vegetation and peat; } \\
\text { trail may be wetter than surrounding area }\end{array}$ \\
\hline 2 & $\begin{array}{l}\text { trail wetter than surrounding area; thaw } \\
\text { subsidence indistinct or patchy }\end{array}$ \\
\hline 3 & trail a trough due to thaw subsidence \\
\hline \multicolumn{2}{|c|}{ Change in plant species composition } \\
\hline 0 & no observable composition change \\
\hline 1 & $0-5 \%$ species composition change \\
\hline 2 & $6-25 \%$ species composition change \\
\hline 3 & $\begin{array}{l}>25 \% \text { species composition change, resulting } \\
\text { in major change in vegetation type }\end{array}$ \\
\hline
\end{tabular}

Each plot was assigned a disturbance rating (Table 2) adapted from a system presented in Radforth (1972). Each plot was assigned a vegetation type and was rated for six disturbance factors: difference between the disturbed and reference plot in percent total vegetative cover, percent shrub cover, and percent exposed soil; impact to microscale surface structure; trail compression or subsidence; and change in plant species composition. These measures were used to assign a summary disturbance rating. This rating was either the same as the rating for vegetative cover, or higher if one of the other factors was rated as high. The vegetation types and initial disturbance ratings were used to stratify the plots for analysis.

Point sampling (Kent and Coker 1999) was used to quantify percent cover of plant species in disturbed and reference plots. In each $4 \times 30 \mathrm{~m}$ plot, a vertical point frame was used to sample 20 points (spaced at $20-\mathrm{cm}$ intervals) on each of 10 evenly spaced $4 \mathrm{~m}$ long transects, for a total of 200 points per plot. To obtain cover estimates, a pin was lowered from the frame at each point and each species intercepted by the pin was recorded. Plant cover data were collected in midsummer near peak biomass. Plant nomenclature followed the PLANTS Database (USDA 2009).

Soils and soil ice were described in 1985 at the reference plots, to determine if natural subsurface characteristics affected initial disturbance and subsequent recovery in adjacent disturbed plots. At each plot, five soil pits were sampled at 5-m intervals. Soil horizons were measured and described following Bates et al. (1982). A $75 \mathrm{~mm}$ diameter permafrost core was used to obtain soil samples in permafrost. Excess soil ice content was estimated at 18 plots that did not have rocky soil. The upper $30 \mathrm{~cm}$ of frozen soil from each core was removed and thawed, and the volume of water in excess of soil saturation was decanted and measured. Excess ice content was calculated as the percentage of the total core volume: $I=$ $100 V_{\mathrm{i}} / V_{\mathrm{c}}$ and $V_{\mathrm{i}}=1.09 V_{\mathrm{w}}$, where $V_{\mathrm{i}}$ is the volume of excess ice in the core, $V_{\mathrm{c}}$ is the the volume of the core, $V_{\mathrm{w}}$ is the volume of water in excess of soil saturation in the core, and the coefficient of expansion for water to ice is 1.09. Vertical ice wedges were avoided, so ice content refers to segregated ice held in the soil matrix.

Disturbance levels and depth of seasonally thawed soil above permafrost (thaw depth) were monitored at an additional 60 plots in 1984, 1985, 1986, 1988, 1991, 1994, 1998, and 2002. Plant cover was not sampled. Thaw depth was estimated by probing to frozen soil with a calibrated steel rod. Depths were probed at 30 points along transects in disturbed and reference plots. Measurements were taken in early August, near the time of maximum annual thaw. Thaw-depth response was modeled similarly to the plant cover data. The model includes 49 plots that did not have rocky soil; no riparian types are represented.

\section{Data analysis}

A model-based approach using spatial and temporal autocorrelation was used, rather than a design-based method, because plots were not chosen using a probability-based sampling scheme (for a discussion, see Ver Hoef 2002). Modeling random errors as autocorrelated in space and time allows valid statistical inference on regression parameters in a model-based approach (Ver Hoef and Cressie 2001).

Models were created for thaw depth and for six plant growth forms: deciduous shrub, evergreen shrub, graminoid, forb (including horsetails), lichen, and bryophyte. Vegetation community types with few plots were aggregated with a similar type for modeling plant growth forms: the two shrub tundra plots were included with tussock tundra, and one wet sedge plot was included with sedge-willow tundra (Table 1). Aggregation was not necessary for the thaw-depth model because of larger sample size.

We analyzed our data with a nonlinear space-time model: 


$$
\begin{aligned}
Y_{i, j}(\mathbf{s}, t)= & \pi_{i j}\left(\beta_{0, i}+\beta_{1, i} t+\beta_{2, i} t^{2}\right) e^{-t / \rho_{i}}+Z(\mathbf{s} ; t)+\delta(t ; \mathbf{s}) \\
& +\varepsilon(\mathbf{s}, t)
\end{aligned}
$$

where $Y_{i, j}(\mathbf{s}, t)$ is the response variable (i.e., the percent cover in disturbed plots minus the percent cover in the reference plots for a particular plant growth form) for the $i$ th vegetation class and the $j$ th disturbance level at spatial location $\mathbf{s}$ in year $t$. The deterministic part of the nonlinear model is composed of a second-order polynomial in time $\left(\beta_{0, i}+\beta_{1, i} t+\beta_{2, i} t^{2}\right)$ for each vegetation type. The multiplier $e^{-t / p_{i}}$ shrinks the model toward zero over time, allowing recovery from disturbance. We scaled the basic curve with $\pi_{i j} ; j=1,2$, or 3 for low, medium, and high initial disturbance (see Table 2; note that no 0-level disturbance was recorded) to allow for differences among initial disturbance levels by vegetation type. For parameter identifiability, we set $\pi_{i 3}=1$, so $\pi_{i 2}$ and $\pi_{i 1}$ are relative to $\pi_{i 3}$. In general, we expected $\pi_{i 3}$ $>\pi_{i 2}>\pi_{i 1}$, but we allowed $\pi_{i 2}$ and $\pi_{i 1}$ to be up to twice as large as $\pi_{i 3}$ to test whether initial disturbance has a significant effect on fitting the curves.

These curves will not be perfect predictors of the response variable. We expected that residuals from the model will still have spatial and temporal patterns, so we add three random effects. The spatial random effect is $Z(\mathbf{s} ; t)$. We assumed that the spatial effects were autocorrelated within a given year $t$, but independent across years. We used an exponential autocorrelation model:

$$
\operatorname{cov}[Z(\mathbf{s} ; t), Z(\mathbf{r} ; u)]=C_{z}(\mathbf{h})=\theta_{s} \exp \left(-\|\mathbf{h}\| / \alpha_{s}\right) I(t=u)
$$

where $\mathbf{h}=\mathbf{s}-\mathbf{r}$ and $\|\mathbf{h}\|$ is the Euclidean distance between any two points $\mathbf{s}$ and $\mathbf{r}$ in space and $I(\cdot)$ is the indicator function. Note that we allowed a separate realization of the random effects for each year (that is, the "surface" was not fixed across years), but for estimation stability the parameters that control them, $\theta$ and $\alpha_{\mathrm{s}}$, are common for all years.

We also assumed that the temporal random effects were autocorrelated within a given location $\mathbf{s}$, but independent among locations. We again used an exponential autocorrelation model:

$$
\operatorname{cov}[\delta(t ; \mathbf{s}), \delta(u ; \mathbf{r})]=C_{\delta}(h)=\theta_{t} \exp \left(-|h| / \alpha_{t}\right) I(\mathbf{s}=\mathbf{r})
$$

where $h=t-u$ is the difference between any two times $t$ and $u$. We assumed that spatial random effects were independent among time periods. This allowed a separate realization of the random effects for each site (that is, the "time series" was not fixed across sites), but the parameters that control them were common to all sites. Finally, we added a component of uncorrelated errors (often called the "nugget" [subscript n] effect in geostatistics); $\varepsilon(\mathbf{s}, t)$. We assumed that $\operatorname{var}(\varepsilon(\mathbf{s}, t))=\theta_{\mathrm{n}}$ and $\varepsilon(\mathbf{s}, t)$ is independent of $\varepsilon(\mathbf{r}, u)$ when $(\mathbf{s} \neq \mathbf{r})$ or $(t \neq$ u).

Although it is reasonable to expect that there are real differences in the curves for each vegetation type by disturbance class, there were not enough samples to reliably estimate each of these curves if we simply subset the data. Instead, we used a Bayesian hierarchical model (BHM); see Cressie et al. (2009) for a recent discussion regarding ecological data. We assumed that $\beta_{0, i}$ was drawn from a normal prior distribution $\beta_{0, i} \sim \mathcal{N}\left(\mu_{\beta 0}\right.$, $\left.\sigma_{\beta 0}^{2}\right) ; i=1, \ldots, n_{\mathrm{veg}}$, where $n_{\mathrm{veg}}$ is the number of vegetation classes, which allowed us to "borrow strength" across the vegetation classes by using "prior" distributions. Likewise, we used the following prior distributions, $\beta_{1, i} \sim \mathcal{N}\left(\mu_{\beta 1}, \sigma_{\beta 1}^{2}\right), \beta_{2, i} \sim \mathcal{N}\left(\mu_{\beta 2}, \sigma_{\beta 2}^{2}\right), \pi_{1, i}$ $\sim \operatorname{UNIF}\left(0,2 \mu_{\pi 1}\right), \pi_{2, i} \sim \operatorname{UNIF}\left(0,2 \mu_{\pi 2}\right)$, and $\rho_{i} \sim$ $\operatorname{UNIF}\left(0,2 \mu_{\rho}\right)$. Using these priors, estimates of each parameter, for example $\pi_{1, i}$, will center around the mean of the prior distribution $\left(\mu_{\pi 1}\right.$, for this example) when there is little or no data for that parameter in the $i$ th vegetation class. Details on fitting the Bayesian hierarchical model are given in Appendix A.

Note that this BHM was too complicated for model selection methods, as many BHMs are. There is little tradition in model selection for these types of models; see Cressie et al. (2009). Instead we tried to develop a model that was robust, where the spatial and temporal autocorrelation absorb lack of fit, which can still be spatially and temporally patterned. The functional forms that we chose for the quadratic in time, the temporal decay, and the multiplier for disturbance type were based on functions that would fit the data and have interpretable parameters. We assessed the model using sensitivity analysis, which is included in Appendix A.

\section{RESULTS}

\section{Plant cover}

The temporal response curves show that different types of plants had very different recovery patterns after disturbance from winter seismic exploration (Fig. 2). After initial decreases in cover for all types of plants, patterns of recovery over the next 18 years varied from rapid recovery to pre-disturbance levels, to greatly increased cover, to slow and incomplete recovery. Figs. 3-5 present response curves for three plant growth forms that represent the range of differing responses to disturbance, including response to three different levels of initial disturbance in five vegetation types. Graphs for all six growth forms are in Appendix B.

Graminoid cover (sedges, grasses) at non-riparian sites showed moderate initial decreases, but then increased rapidly above reference levels within five years, especially after higher level initial disturbance (Fig. 3). Cover peaked between five and eight years and then decreased gradually. The response was earliest for sedge-willow tundra, in which graminoids increased above reference levels in every disturbed plot, even with low initial disturbance. The effect was delayed, but lasted longest, for plots with high initial disturbance on sedge Dryas tundra and sedge tussock tundra.

Deciduous shrubs, forbs, and lichens had similar recovery patterns. Deciduous shrubs were severely 


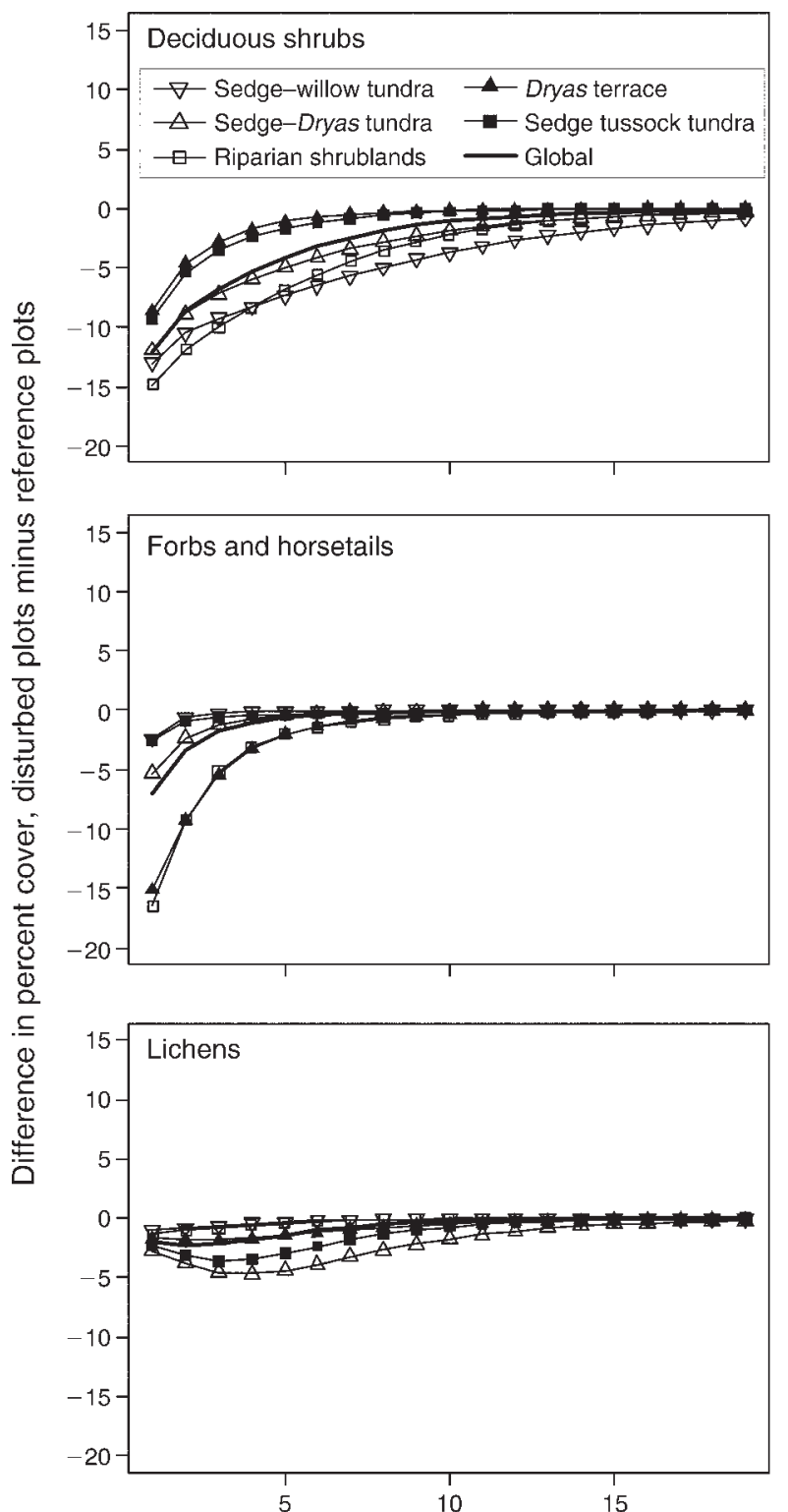

Time since initial disturbance (yr)
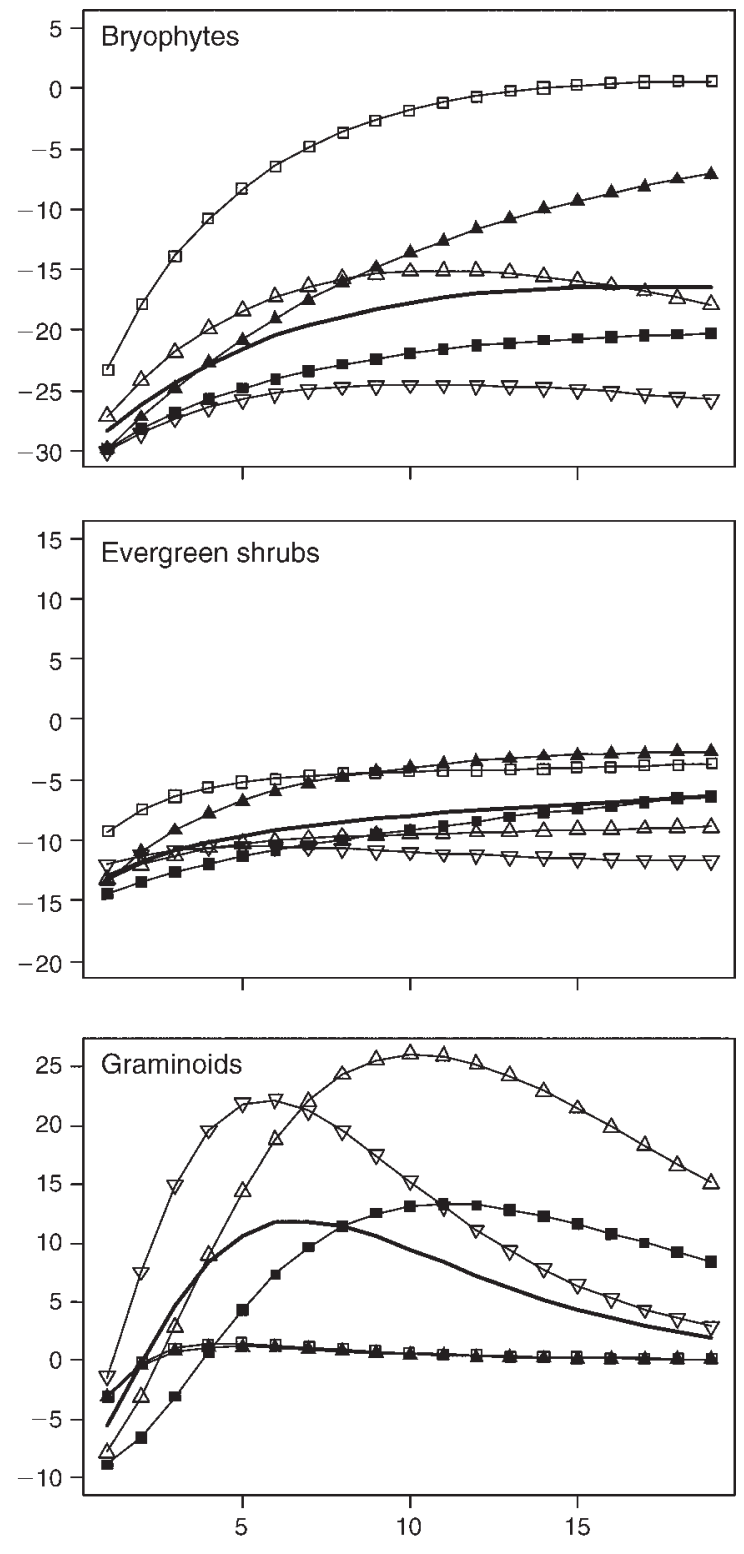

Time since initial disturbance (yr)

FIG. 2. Fitted models for high-level disturbance for six plant growth forms in five vegetation types. Differences are percent cover in disturbed plots minus percent cover in reference plots.

damaged in all vegetation types, especially sedge-willow tundra and riparian shrublands (Fig. 4). Higher disturbance levels caused greater decreases in cover, but all levels recovered rapidly during the first 10 years. For forbs, large initial decreases in cover were followed by rapid recovery in the first five years. Lichen recovery was slower. Live lichen cover continued to decrease on trails for the first five years after disturbance, perhaps because lichens on displaced chunks of organic mat died over several years.

Bryophytes (mosses and liverworts) suffered large decreases in cover after medium- to high-level distur- bance (Fig. 5). At Dryas terrace and riparian shrubland sites, bryophyte cover approached reference values after 18 years, even after extreme initial reductions. Recovery of bryophytes was slow and still incomplete, however, in the other vegetation types. One-third of all plots still had decreases in bryophyte cover of $\geq 20 \%$ in 2002 (e.g., $54 \%$ on reference and $34 \%$ on trail). Evergreen shrubs showed recovery patterns similar to those for bryophytes. Cover was initially greatly reduced and recovery was generally poor. The models do not indicate any recovery trends for either bryophytes or evergreen shrubs in sedge-willow tundra and sedge-Dryas tundra. 

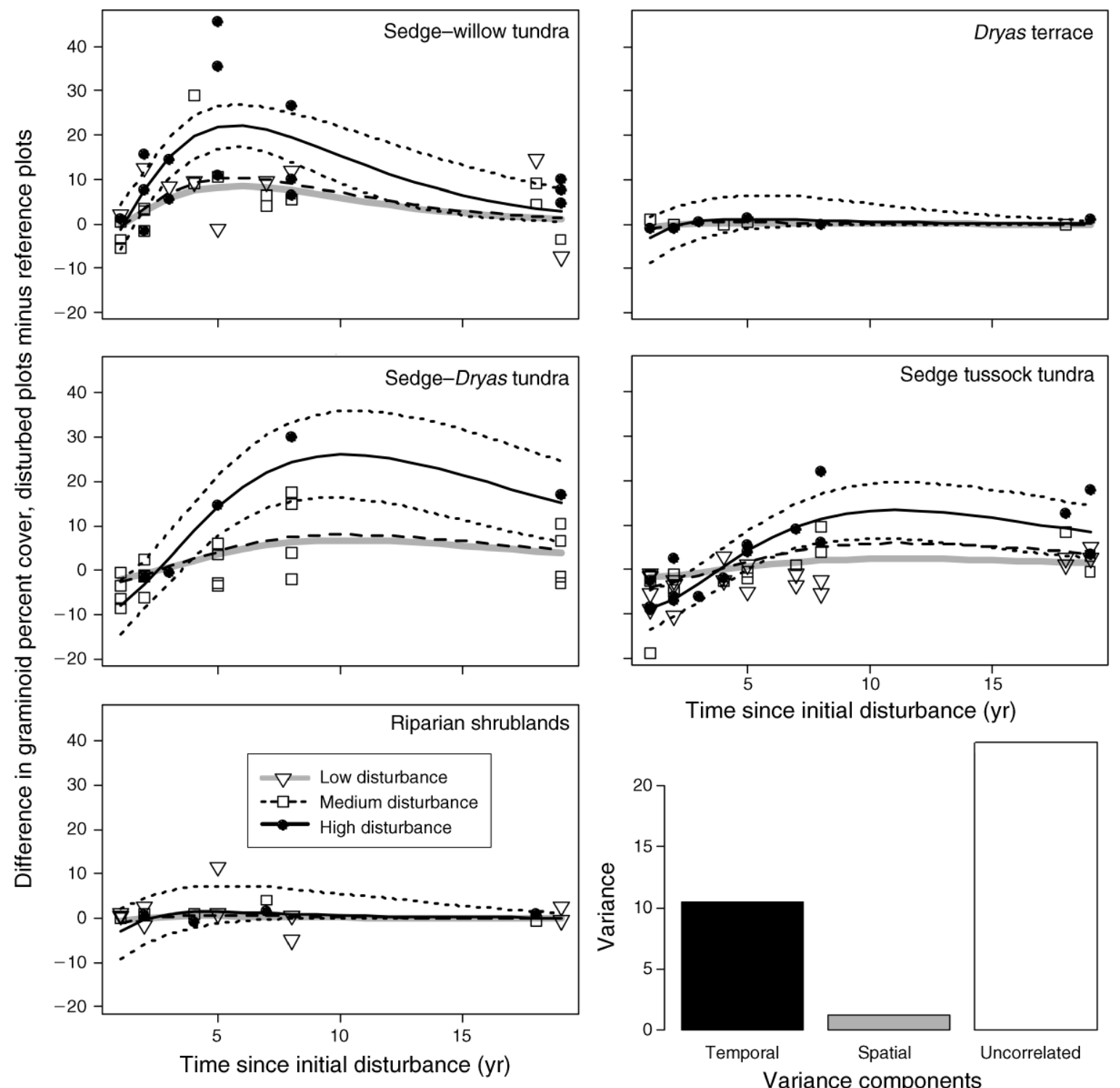

Time since initial disturbance $(\mathrm{yr})$

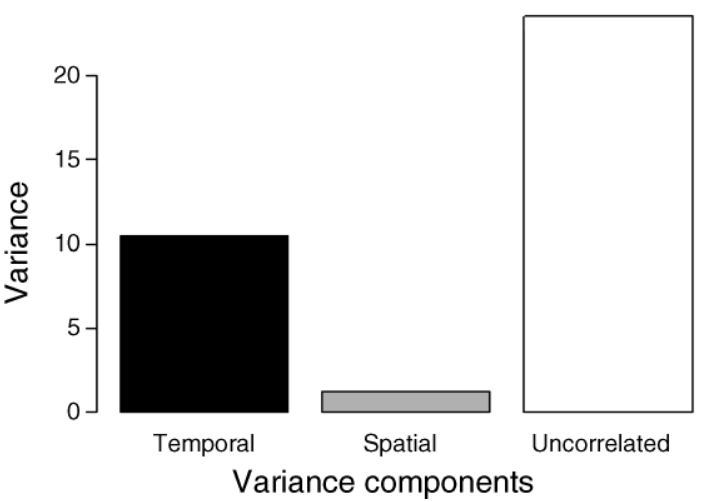

FIG. 3. Fitted models of the response of graminoids to three levels of initial disturbance in five vegetation types. Differences are percent cover in disturbed plots minus percent cover in reference plots. The short-dashed line is the $95 \%$ credibility envelope of the fitted model for the highest level of initial disturbance. The variance components, which show the relative partitioning of variability in the data, are $\theta_{\mathrm{t}}$ (temporal), $\theta_{\mathrm{s}}$ (spatial), and $\theta_{\mathrm{n}}$ (nugget [uncorrelated]).

\section{Depth of thawed soil}

Depth of thawed soil in late summer, which affects the permafrost surface and potential thaw settlement, was initially greater on trails than in the reference plots (Fig. 6). Depths continued to increase 3-8 years after disturbance before recovering. Sedge-willow tundra with medium- or high-level disturbance had the largest increase in thaw depths $(5-20 \mathrm{~cm})$ for the first 3-5 years, followed by stabilization to reference levels within 10 years. Wet sedge tundra had a similar pattern, but the initial increases were only half as great. In tussock tundra and sedge-Dryas tundra, thaw depths increased for about five years before slowly recovering to reference levels by 18 years. Response of thaw depths in shrub tundra was anomalous in that depths did not continue to increase after the first year. Riparian vegetation types (riparian shrublands and Dryas terrace) were not sampled due to rocky soil. All vegetation types showed a consistent trend in greater thaw depths in response to higher levels of disturbance.

\section{Ground ice}

Excess ice in the soil (the amount of water in excess of what could be held within unfrozen soil pore space) affects thaw settlement after disturbance. Excess ice in 

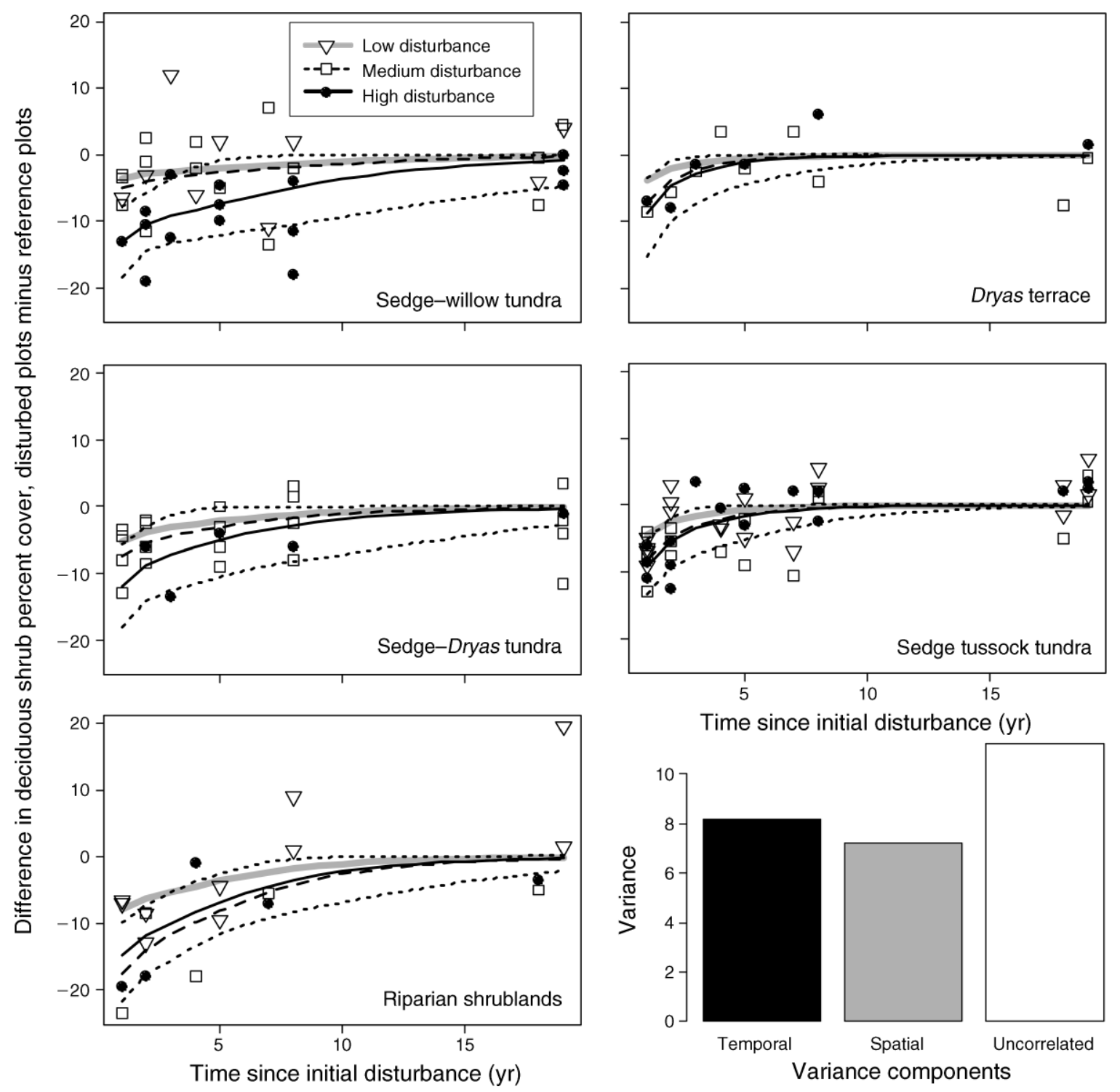

Time since initial disturbance $(\mathrm{yr})$

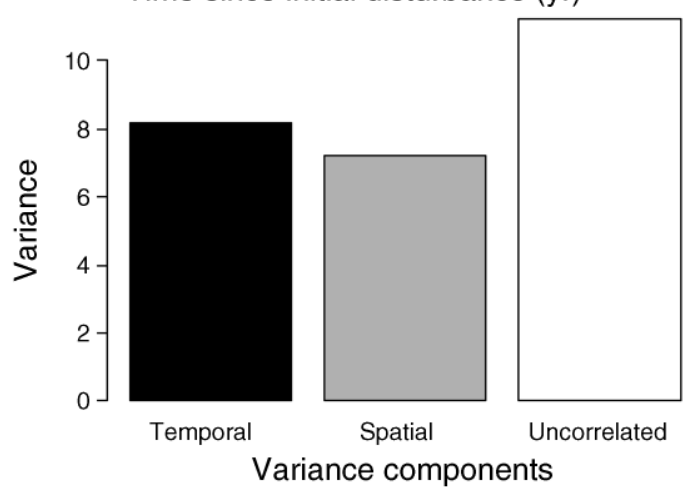

FIG. 4. Fitted models of response of deciduous shrubs to three levels of initial disturbance in five vegetation types. Differences are percent cover in disturbed plots minus percent cover in reference plots. The short-dashed line is the $95 \%$ credibility envelope of the fitted model for the highest level of initial disturbance. The variance components are $\theta_{\mathrm{t}}$ (temporal), $\theta_{\mathrm{s}}$ (spatial), and $\theta_{\mathrm{n}}$ (nugget).

the top $30 \mathrm{~cm}$ of the permafrost ranged from $2 \%$ to $45 \%$ by volume across 18 reference plots sampled. Ice contents were highest for sedge-Dryas tundra and sedge-willow tundra, intermediate for tussock tundra, and lowest for shrub tundra and wet sedge tundra (Fig. 7). Riparian vegetation types were not sampled due to rocky soil, but probably had little ice accumulation because of coarse soil texture.

Greater soil ice content was associated with greater trail subsidence and higher disturbance ratings (Fig. 7). Sedge-Dryas tundra, which had the highest mean excess ice contents, also had the highest frequency of trails with a high subsidence rating (thaw settlement evident; Table 2). Moist sedge-willow and tussock tundra had both intermediate ice and intermediate frequencies of medium-to-high thaw settlement ratings. When all plots were grouped, six of nine plots with $\geq 20 \%$ excess ice had medium or high subsidence ratings, and seven of nine were rated as highly disturbed either initially or else deteriorated to that level by 2002. Of the nine plots with $<20 \%$ excess ice, only two showed detectable subsidence and none was rated as highly disturbed. Subsidence often was not apparent until after the first few years.

\section{DiscusSION \\ Vegetation}

Tundra ecosystems showed low resistance to vehicle damage during winter, with initial decreases in cover for 

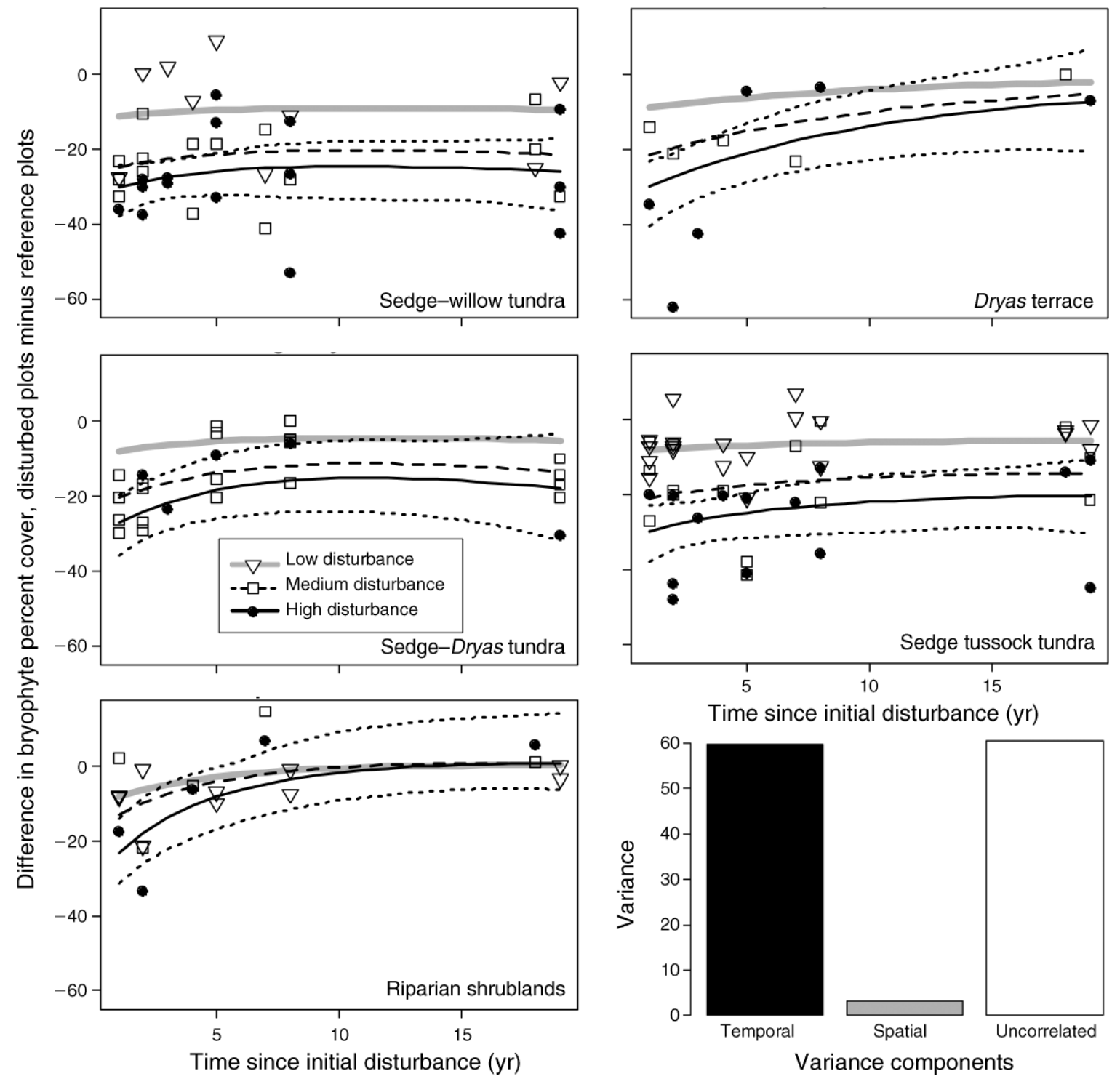

Time since initial disturbance $(y r)$

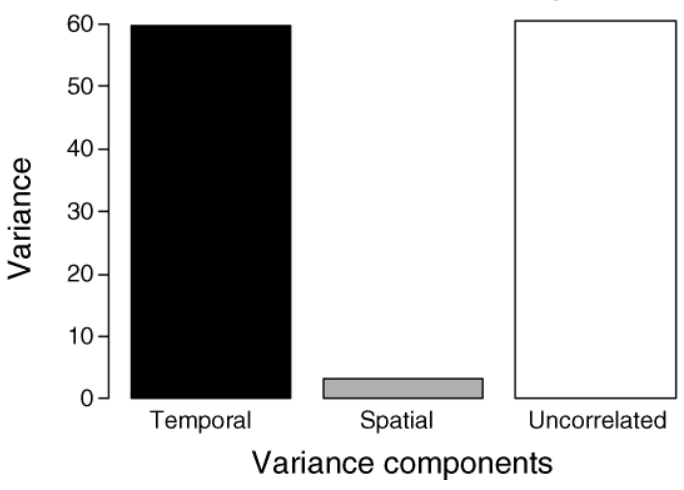

FIG. 5. Fitted models of response of bryopohytes to three levels of initial disturbance in five vegetation types. Differences are percent cover in disturbed plots minus percent cover in reference plots. The short-dashed line is the $95 \%$ credibility envelope of the fitted model for the highest level of initial disturbance. The variance components are $\theta_{\mathrm{t}}$ (temporal), $\theta_{\mathrm{s}}$ (spatial), and $\theta_{\mathrm{n}}$ (nugget).

all plant growth forms and in all plant community types. Monitoring of recovery over a two-decade period indicated that different plant species and plant communities varied greatly in resilience. Resilience can be defined as the degree, manner, and pace of recovery of an ecosystem to its original state after disturbance (Westman 1978). Many differences can be explained by growth strategies of different species. However, the low resilience of some species and communities cannot be explained without an understanding of the physical changes that occurred on some trails after vehicle traffic due to thawing of ice-rich permafrost.

The dramatic increase in graminoid cover on trails during the first decade was mainly due to vigorous growth of the rhizomatous sedges Eriophorum angustifolium Honck. and Carex aquatilis Wahlenb. In all years of this study, these species had the largest increases in cover above reference levels of any plant species. These resilient species thrive in disturbed areas with moist to wet soil, often to the exclusion of other species. Plant productivity and nutrient analyses in the early years of this study showed large initial increases in tissue nutrients and productivity for these species on trails in 1985 and 1988 (Emers et al. 1995). By 1991, however, the initial nutrient stimulus tapered off. Higher soil moisture on trails from compressed soil or subsidence allows more summer heat transfer to the soil, increasing soil temperature, decomposition rates, and nutrient 

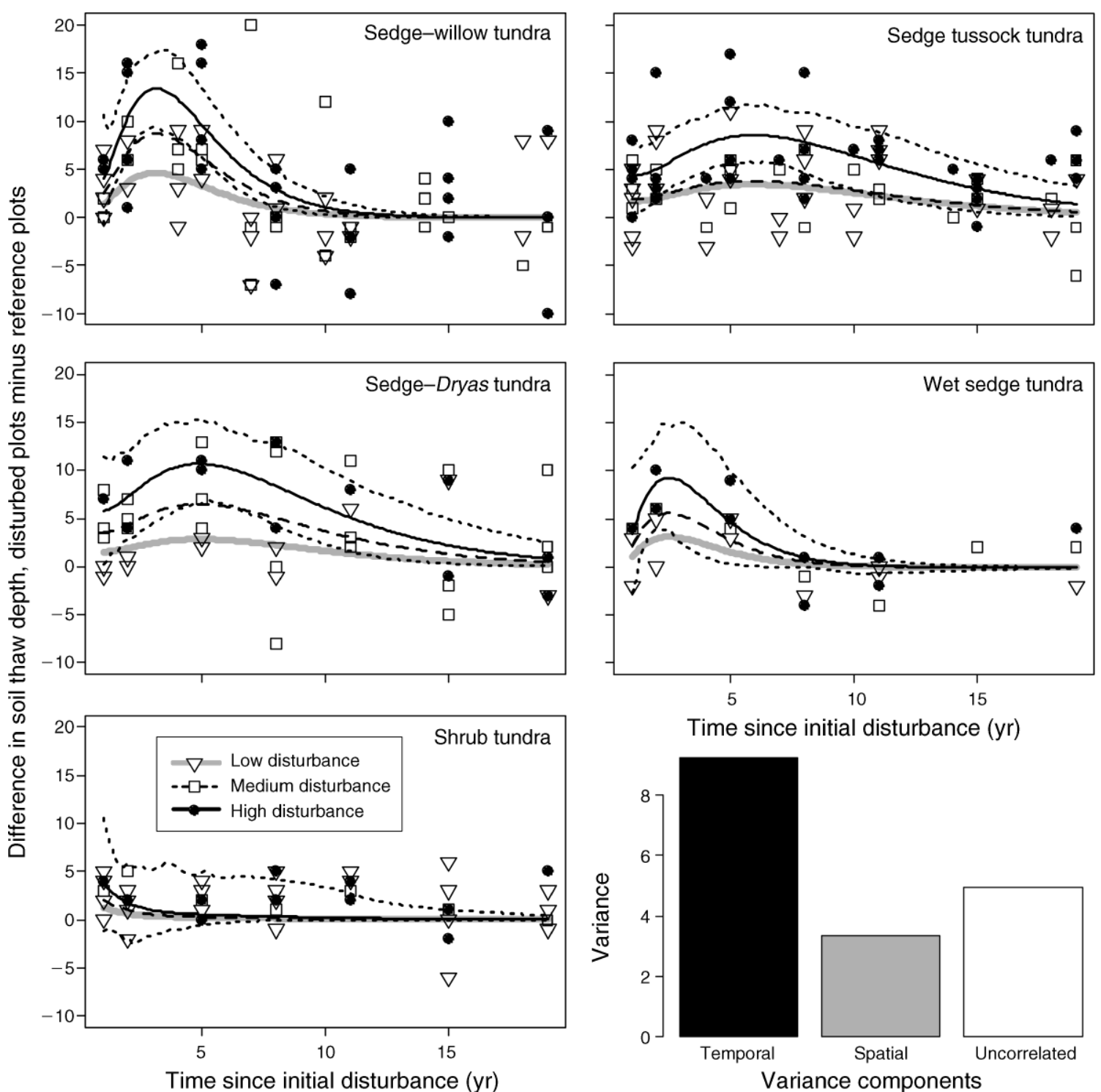

Time since initial disturbance (yr)

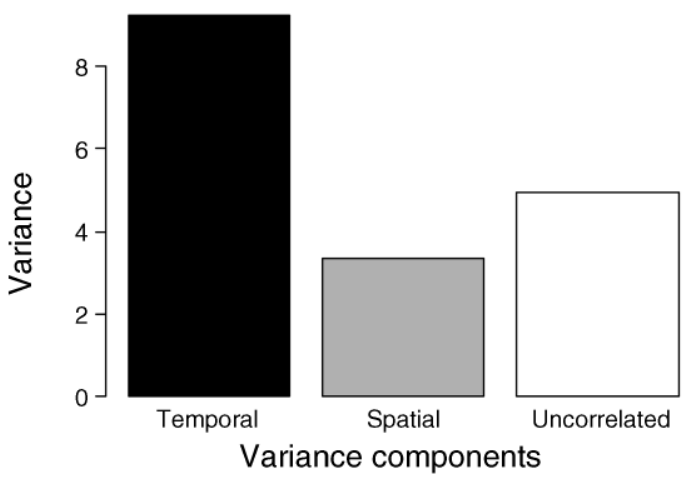

FIG. 6. Fitted models of seasonal soil thaw depth to three levels of initial disturbance in five vegetation types. Differences are depth in disturbed plots minus depth in reference plots $(\mathrm{cm})$. The short-dashed line is the $95 \%$ credibility envelope of the fitted model for the highest level of initial disturbance. The variance components are $\theta_{\mathrm{t}}$ (temporal), $\theta_{\mathrm{s}}$ (spatial), and $\theta_{\mathrm{n}}$ (nugget).

mineralization, at least transiently (Chapin and Shaver 1981). In contrast, the tufted sedges Eriophorum vaginatum L. and Carex bigelowii Torr. had few increases in nutrients and productivity after disturbance (Emers et al. 1995). These two species form raised tussocks and hummocks that were damaged even at low levels of disturbance. They generally did not respond opportunistically to disturbance, but did achieve modest increases above reference levels in some plots by 2002 . Grasses increased above reference levels after disturbance on sites where surface soil remained dry. Some trails on sedge-Dryas tundra were highly visible during the first five years after disturbance, due to dense grass, mainly Arctagrostis latifolia and several species of Poa
L. Grass cover decreased toward reference values after 10 years and trails became less visible. Increased grass cover in the first decade after disturbance has been reported by Hernandez (1973) and others, but the longer term outcome was unknown.

Graminoid cover on trails decreased from 10-18 years, but all of the highly disturbed non-riparian plots still had more graminoid cover on the trails than in references in 2002. Some trails that subsided were still dominated by rhizomatous sedges and remained highly visible up to 24 years after disturbance and are not expected to return to the original vegetation for many more decades (Fig. 8). 

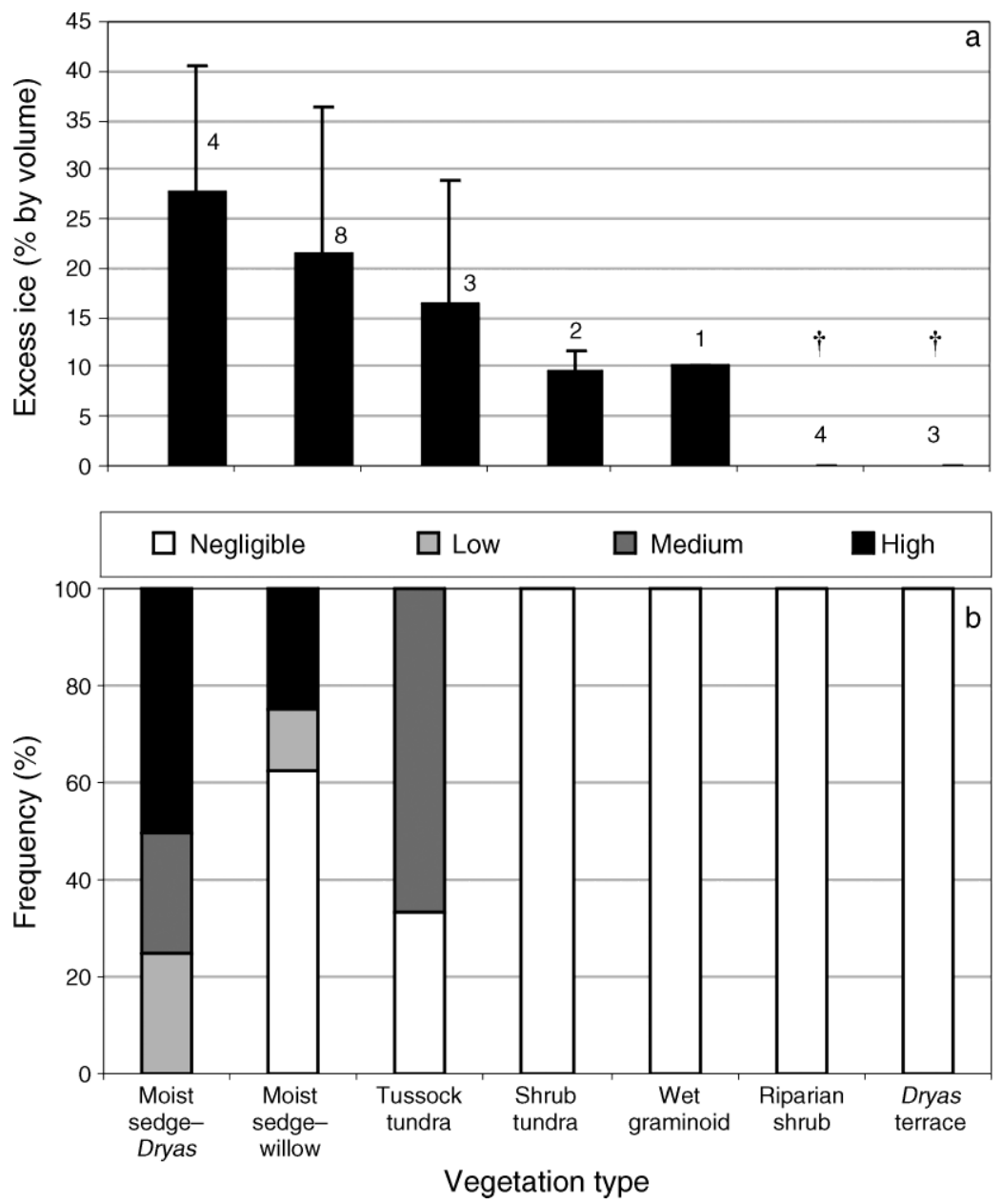

FIG. 7. (a) Excess ice contents (mean and upper portion of $95 \% \mathrm{CI}$ ) in the top $30 \mathrm{~cm}$ of permafrost in undisturbed tundra in 1985 (number of plots sampled is given above bars). Daggers indicate vegetation types that were not sampled due to gravel, where excess ice was assumed to be $0 \%$. (b) Frequency of four levels of soil subsidence (negligible through high) 18 years after disturbance on an adjacent trail.

Deciduous shrubs included shrub birch (Betula nana L. ssp. exilis (Sukatsch.) Hulten ) and 13 species of willow (Salix L.). They recovered well within 10 years after disturbance, but did not increase above reference levels. Many deciduous shrubs, particularly willows, are well adapted to disturbance, such as river flooding and grazing, and quickly resprout from buds or roots. Dwarf willows that grew on drier sites, such as Salix phlebophylla Anderss., recovered more slowly than erect, moist-site willows such as S. pulchra Cham. Kemper and Macdonald (2009a) reported that winter seismic trails 20-30 years old had shrubbier vegetation than surrounding tundra on the partially forested Mackenzie Delta, Canada, mainly due to increases of the boreal forest species of shrub birch, Betula glandulosa Michx. They suggested that a warming climate could have favored shrub regrowth over other plants. In artificial tundra fertilization and warming experiments, the arctic shrub birch Betula nana L. ssp. exilis (Sukatsch.) Hulten increased in dominance over willows and all other plants (Bret-Harte et al. 2001). In our study, the willow Salix pulchra and, to a lesser extent, Betula nana, increased annual twig productivity and tissue nutrient content on trails for the first three or four years after disturbance, but the effect was negligible by eight years (Emers et al. 1995).

In contrast to deciduous shrubs, evergreen shrubs showed poor recovery 18 years after disturbance. The dwarf ericaceous shrubs Vaccinium vitis-idaea L. and Ledum decumbens (Aiton) Lodd. Ex Steud. showed less post-disturbance increase in productivity and leaf nutrient content on these trails than deciduous shrubs (Emers et al. 1995), indicating a more conservative response to change. Starr et al. (2008) reported that these two ericaceous shrub species had the lowest maximum photosynthetic capacity of all the tundra plant species that they tested. They also store more of their nutritional reserves above ground than deciduous 

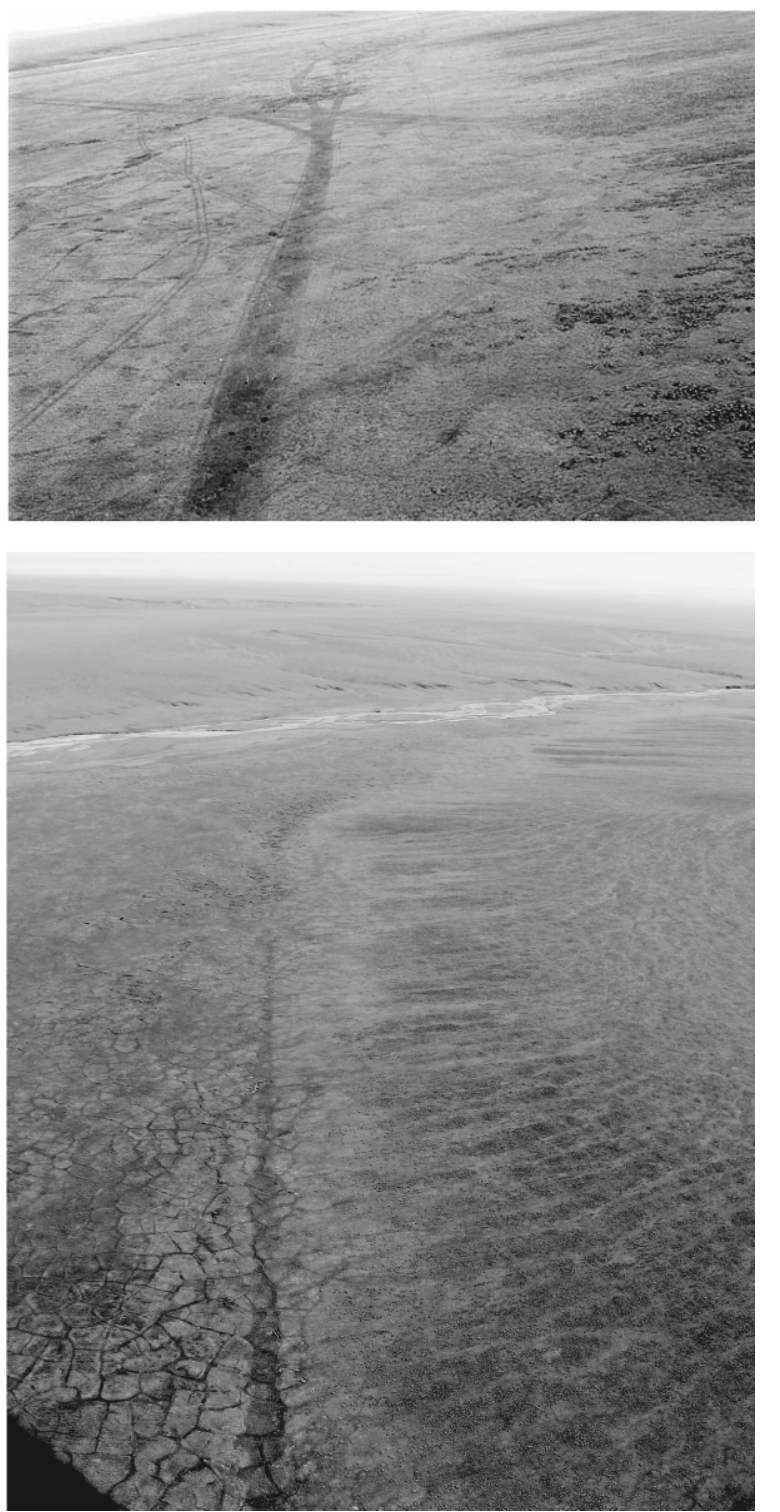

FIG. 8. Aerial views of a highly disturbed camp-move trail made in winter of 1985 on moist sedge-willow tundra, photographed in July 1985 (above) and July 2007 (below). An undisturbed reference plot to the left of the trail had a soil excess ice content of $28 \%$ in 1985 . Thawing of soil ice and ice wedges led to trail subsidence. The trail remained wetter and greener than surrounding tundra in 2007, with more rhizomatous sedge cover and less feathermoss cover. Photos are courtesy of the U.S. Fish and Wildlife Service.

shrubs, so they may take longer to recover after stem breakage. Poor evergreen shrub recovery was often associated with wetter soil conditions on trails (Fig. 9), but recovery was also poor on drier sites. Riparian shrublands and Dryas terrace sites had Dryas integrifolia M. Vahl. of the rose family, which recovered better than ericaceous shrubs. Poor recovery of ericaceous shrubs, coupled with increased sedge (Eriophorum angustifolium), caused some trails on tussock tundra to remain visible for at least 23 years, even as the tussocks recovered (Fig. 10).

Many forb species successfully recolonized trails in the early years (Emers et al. 1995), but were not more abundant than in the surrounding tundra. Forb species diversity was greatly reduced on trails through 1991, but was similar to references in 2002.

Lichen cover changed little and recovered rapidly, mainly due to early colonization of exposed mineral soil and peat by crustose lichens such as Ochrolechia frigida (Sw.) Lynge and Lecanora epibryon (Ach.) Ach. Other lichens usually recovered slowly, but nearly completely, by 2002 .

Bryophytes have greater cover in the study area than all other plant growth forms combined and are important ecologically for insulating the underlying permafrost from summer air temperatures. They initially suffered large reductions in cover on the trails, perhaps because they lack roots and are more weakly anchored to the substrate than vascular plants. At non-riparian sites there was little recovery, even after 18 years. In contrast, at riparian sites bryophytes recovered to near reference levels after 18 years, even after large initial reductions. Mosses, such as Distichium capillaceum (Hedw.) Bruch \& Schimp. and Ditrichum flexicaule (Schwagr.) Hampe, recolonized bare mineral soil, which was common at riparian sites. The longest lasting damage was the destruction of mats of pleurocarpous feathermosses, which exhibit the "perennial stayer" life strategy (During 1979) and are evidently slow-growing, late-successional species. The common feathermosses Tomenthypnum nitens (Hedw.) Loeske and Hylocomium splendens (Hedw.) Schimp. seldom recovered in sedgewillow tundra and sedge-Dryas tundra, but did show some recovery in about one-half of the other plots. The common liverwort Ptilidium ciliare (L.) Hampe and Sphagnum L. mosses were greatly reduced on trails and showed no recovery. These four bryophyte taxa had the largest persistent decreases of any plant species. Most other bryophyte taxa showed more recovery, although regrowth was slow and often not complete by 2002 .

The inability of bryophytes to recover two decades after disturbance may be explained by low growth rates; disadvantage in competition for light and moisture against faster growing and taller stature vascular plants, especially rhizomatous sedges; and difficulty recolonizing peat substrates that can dry out rapidly during dry weather. Bryophytes generally lack a vascular system, are dependent on a transient external water supply, and must be well hydrated to maintain active metabolism (Longton 1988). Individual bryophyte species also have narrow moisture tolerances for optimal growth and many species reproduce only vegetatively in the Arctic (Callaghan and Collins 1981). This may limit recolonization by new species if site conditions change after disturbance.

The results from these plots showing good recovery for most growth forms and vegetation types under low 

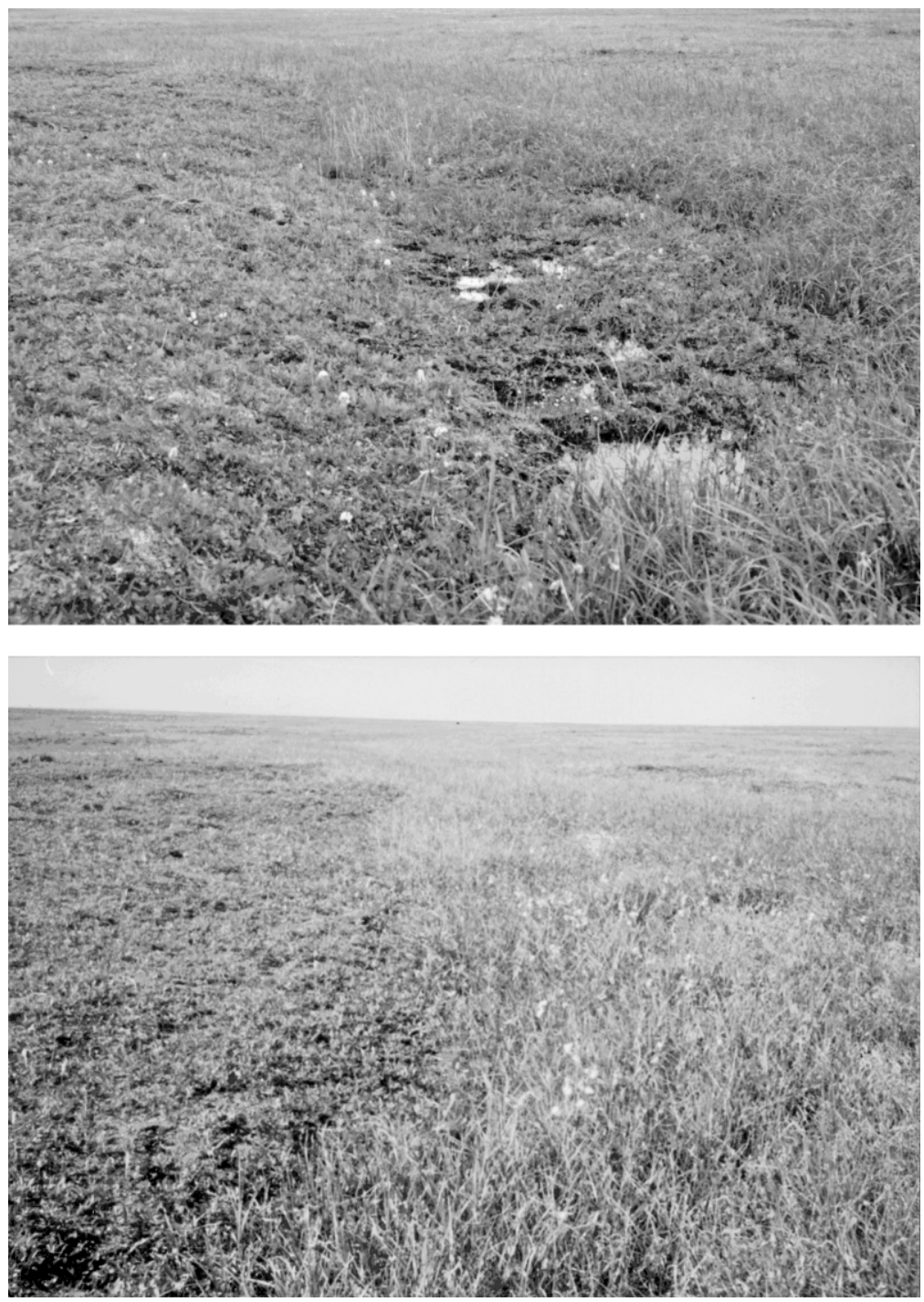

FIG. 9. Repeat photographs of a seismic trail across a raised area with dwarf shrubs and moss, with a natural trough on the right. The 1989 photograph (above) shows collapse of the edge of the raised area into the adjacent trough after vehicle traffic during 1985 exploration. The 1993 photograph (below) shows the same location after sedges had replaced the shrubs and mosses due to the altered moisture regime. Photos are courtesy of the U.S. Fish and Wildlife Service.

to moderately disturbed conditions, and poor recovery under highly disturbed conditions, are consistent with a companion study of rapidly assessed random-systematic plots on these trails (Appendix C). That study, which involved rating of disturbance at a sample of 200 points on the trails, revealed that the percentage of plots that remained disturbed decreased from $79 \%$ in 1985 to $48 \%$ in $1989,11 \%$ in $1993,6 \%$ in 1998 , and $5 \%$ in 2009. For points that initially had low-level disturbance, recovery was rapid. About one-quarter of all points had medium- to high-level disturbance in 1985 and these recovered more slowly. Medium and high level disturbance did not persist until 2009 unless trail subsidence occurred.

\section{Permafrost}

The presence of permafrost greatly increases the complexity of ecological responses to disturbance in the Arctic, due to feedbacks between soil topography, hydrology, and ground ice. Initial minor thaw settlement caused by disturbance can lead to water impoundment, decreased albedo, and increased heat flux, which in turn causes more thaw settlement (Lawson 1986). This thaw settlement and changing hydrology causes shifting recovery patterns away from the original site conditions toward new plant communities that make some trails remain visible for many years.

The amount of ground ice was an important factor determining the long-term effects of seismic trails. There 


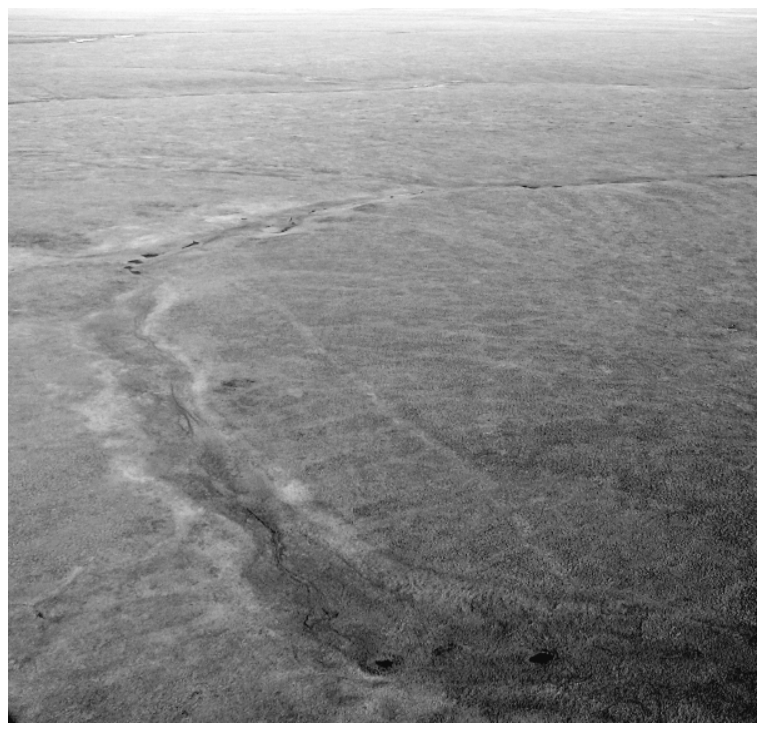

FIG. 10. Trail on sedge-tussock tundra, made by campmove vehicles in 1984 and photographed in 2005. The trail was still visible after 21 years because it had fewer evergreen shrubs and more sedges than surrounding tundra. The photo is courtesy of the U.S. Fish and Wildlife Service.

is a substantial risk of thaw subsidence on the coastal plain of northern Alaska because of the high volume of ice at the top of the permafrost (Nelson et al. 2001). Ground ice varies widely across the landscape in association with landscape age, soil texture, soil organic matter accumulation, and drainage (Jorgenson et al. 1998, Pullman et al. 2007). Active floodplains with relatively young sediments and sandy textures have little excess ice. Our riparian sites (riparian shrublands and Dryas terraces) had good vegetation recovery, even after extreme initial damage, because the ice-poor gravel substrate did not subside and conditions for plant growth did not change. Relatively old coastal plain deposits with loamy soils can have high excess ice contents. Trails on upland sites with low initial disturbance usually recovered well, but those with medium or high disturbance often caused subsidence and long-term changes in plant community composition.

Much of the persistent disturbance on seismic trails was associated with degrading ice wedges. In addition to excess ice in the soil matrix, ice wedges form massive ice just below the thawed soil layer and are particularly sensitive to disturbance and climate change (Jorgenson et al. 2006). We did not quantify ice wedges in our study plots, but their presence could be ascertained by ground surface patterns. One-third of our study area has ground surface patterns indicative of subsurface polygonal networks of ice wedges (Jorgenson et al. 1994). Icewedge induced troughs frequently became larger after medium- and high-level disturbance, especially in sedgeDryas tundra and sedge-willow tundra. Thermokarst ponds gradually developed over ice-wedge troughs on some trails. These observations indicate that damage can increase gradually over long periods, thaw settlement can occur even at moderate levels of disturbance, and that stabilization will take much more than two decades at the more damaged sites on ice-rich substrates.

\section{Implications for management}

Seismic exploration has been conducted every winter on the North Slope of Alaska since at least 1976, and trails in various stages of recovery are visible from the air during the summer in many areas. Current "3-D" seismic exploration, which produces three-dimensional images of subsurface structures, creates a much denser grid of seismic lines $(0.2-0.5 \mathrm{~km}$ apart $)$ than the "2-D" exploration in the Arctic NWR during the 1980s (5-20 $\mathrm{km}$ apart). The National Research Council (NRC 2003) estimated that $51500 \mathrm{~km}$ of trails were made on the North Slope between 1990 and 2001, and that another $43450 \mathrm{~km}$ would be surveyed in the following 10 years. Precise estimates cannot be made because locations of the trail networks are not available to the public.

There are numerous factors that affect disturbance and recovery, such as vehicle type, traffic patterns and number of passes, vegetation, soil, and snow depth. We will summarize recommendations for managing many of these factors to reduce impacts.

Sensitive vegetation should be avoided to help reduce damage. Identifying and avoiding sensitive areas will require detailed vegetation maps and a management strategy to implement appropriate trail routing. Vegetation types dominated by sedges and deciduous shrubs recover relatively well, whereas vegetation types dominated by evergreen shrubs are much slower to recover (Appendix D). Sensitive vegetation types, such as sedgeDryas tundra and tussock tundra, should be avoided. Routing of vehicles around riparian shrublands is not necessary, given the rapid recovery rates.

Areas of high ground ice, especially terrain with abundant ice wedges, should be avoided. Such areas are prone to thaw settlement, which creates long-term changes in topography and surface hydrology, such as channeling flow on slopes and drying of adjacent areas. This will require improved surficial geology maps and a much better knowledge of the nature and volume of ground ice associated with varying terrain types.

Climate change is likely to make permafrost even more sensitive to seismic exploration activity in the future. We speculate that warming in the past two decades has exacerbated some of the thawing on trails reported in this paper. The trail disturbances in 1984 and 1985 had the unfortunate timing of occurring only a few years before the unusually warm summer in 1989, which probably initiated the widespread degradation of ice wedges observed elsewhere on the North Slope of Alaska (Jorgenson et al. 2006). With climate predicted to get much warmer in the Arctic, enhanced efforts will be needed to avoid medium- to high-level disturbances that we found led to permafrost degradation. 
Sufficient snow cover is important to minimize vehicle damage to tundra. An earlier study of factors affecting seismic impacts in the Arctic NWR reported that snow depths of at least $25 \mathrm{~cm}$ were required to reduce impacts (Felix and Raynolds 1989b). Snow had to be deep enough to cover tussocks in tussock tundra and provide a slab depth of at least $20 \mathrm{~cm}$ over basal hoar frost in sedge-willow tundra. Since 2004, regulations for winter activity on State of Alaska Lands require a mean snow depth of $15 \mathrm{~cm}$ on the flatter coastal plain and $23 \mathrm{~cm}$ in the foothills, which are mainly tussock tundra.

Vehicle weight and track configuration are important determinants of degree of disturbance. Camp trailers pulled by tractors caused more long-term damage in 1984-1985 than seismic survey vehicles. By 2009, 9\% of camp trail plots in a random sample were still disturbed, whereas no seismic line plots showed signs of disturbance. Recent studies in northern Alaska indicate that camp-move vehicles still cause most of the damage that is likely to persist. A survey of impacts from a 1996 seismic exploration program on Alaska's North Slope found that $6 \%$ of seismic lines and $29 \%$ of camp trails had at least medium-level disturbance initially (Jorgenson et al. 2003). A study of disturbance from 1998 seismic exploration by the Bureau of Land Management (BLM, unpublished data) found that $4 \%$ of seismic lines and $63 \%$ of camp-move trails were still disturbed after six years. The third summer after 2006 seismic exploration in the Teshepuk Lake Special Area in northern Alaska, camp-move trails were more visible from the air than seismic trails (Jones et al. 2008; B. M. Jones, personal communication).

Multiple vehicles travelling in the same narrow track caused more initial damage than when vehicles spread out (Raynolds and Felix 1989). High-level disturbance and trail subsidence persisted until 2009 only on narrow camp-move trails. Only slight damage persisted on camp-move trails where vehicles spread out.

Industry has made a concerted effort to change to less damaging vehicles since the mid-1980s. Metal-tracked survey vehicles have been replaced with less damaging rubber-tracked vehicles. Survey vehicles cause less damage and have been easier to upgrade because they are relatively light and propel only themselves. The most damaging camp support vehicles are still in use, however, because camp tractors need weight and traction to pull strings of five or more ski-mounted trailers. In addition to mass, the shearing action of skis can cut the vegetative mat and increase damage. Steeltracked D-7 Caterpillar tractors, which were the highest ground pressure and most damaging vehicles used in 1984-1985 (psi $10.5[=72.4 \mathrm{kPa}]$ ), are still preferentially used for current seismic exploration. Lighter, less damaging rubber-tracked tractors (Case-brand agricultural tractors, psi $4[=27.6 \mathrm{kPa}]$ ) are also used for pulling camp trains, but they are expensive and less reliable because they tend to lose traction on ice, soft snow, and slopes. Loss of traction can increase damage as spinning tracks attempt to regain traction. Thus, efforts to find newer, less damaging vehicles should continue, particularly a replacement for D-7 tractors and strings of camp trailers.

Monitoring of seismic exploration impacts should become routine. Currently, fly-by inspections for fuel contamination, garbage, and trail damage soon after exploration are done to assess impacts, but little documentation is available to the public. A more quantitative and transparent assessment is needed. Monitoring recovery in areas with medium- to highlevel impacts is needed to learn from mistakes and improve management strategies to further reduce impacts.

Although some types of vehicles have been replaced since exploration done in the mid-1980s, the results of our study of impacts associated with exploration during that period are still relevant to exploration with current technology. First, our study provides most of the information available on long-term damage; no new studies with this amount of detail have been initiated (NRC 2003). Second, medium to high levels of damage from seismic exploration are still occurring. Kemper and Macdonald (2009b) report that initial impacts to upland tundra from current exploration on the MacKenzie River Delta, Canada, are similar to, or somewhat greater than, initial impacts reported for trails created during the earliest winter seismic exploration programs in the same area 30 years previously (Bliss and Wein 1972, Hernandez 1973). A recent Environmental Assessment for seismic surveys in northern Alaska stated that "seismic exploration may vary from having no observable effects in some situations to damaging vegetation to the extent that it may take years or even decades to heal. These impacts occur despite existing stipulations on operations, and cannot be further mitigated, given the types of equipment currently used" (BLM 2008).

\section{CONCLuSions}

Monitoring the recovery of winter seismic trails for up to 25 years showed that vehicle traffic over snowcovered tundra can cause long-term changes to plant communities and permafrost stability (Appendix E). Short-term studies of winter vehicle disturbance had predicted only short-term impacts. Early reports predicted that the impacts from the exploration program in the Arctic NWR would be mainly aesthetic and there was not likely to be long-lasting damage. The results of our follow-up study contradict these predictions and highlight the importance of long-term studies.

The amount of ice in the upper permafrost affected the rate of recovery. Trails on ice-poor gravel substrates recovered well even after extreme initial disturbance because the substrate was stable and soil conditions for plant growth did not change. Some trails on ice-rich, fine-grained soils remained disturbed after 25 years because changes in hydrology caused by ground subsi- 
dence led to shifts in vegetation composition. Those trails are unlikely to recover to pre-disturbance conditions.

Given the extent of seismic exploration in the Arctic, cumulative impacts of even small percentages of trails with high disturbance can be significant (NRC 2003). These impacts may not be fully evident from short-term monitoring. No system exists for tracking the seismic trails made every year in Alaska, so large areas of the North Slope have an unknown amount of direct human disturbance. Given the magnitude of ongoing seismic exploration programs and the likelihood that some medium- to high-level damage will occur, industry and regulatory agencies should redouble their efforts to avoid the long-term impacts that we have documented.

\section{ACKNOWLEDGMENTS}

We thank those who worked on this project, especially Martha Raynolds, Mike Emers, Colette Buchholtz, Kris DuBois, Rob Lipkin, Bev Reitz, and Laura Welp. We thank Nancy Felix, who established the study in 1984, and Jerry Stroebele and Glen Elison, who were instrumental in securing continuing funding from the U.S. Fish and Wildlife Service.

\section{Literature Cited}

Bates, D. N., J. M. Belisle, B. H. Cameron, L. J. Evans, R. K. Jones, G. Pierpoint, and B. Van der Broek. 1982. Field manual for describing soils. Ontario Institute of Pedology, University of Guelph. Ontario Institute of Pedology Publication Number 82-1.

Bliss, L. C., and R. W. Wein. 1972. Plant community responses to disturbance in the western Canadian Arctic. Canadian Journal of Botany 50:1097-1109.

BLM (Bureau of Land Management). 2008. Environmental assessment: conduct 3-D seismic, Anadarko. Bureau of Land Management EA \#93476, Anchorage, Alaska, USA.

Bret-Harte, M. S., G. R. Shaver, J. P. Zoerner, J. F. Johnstone, J. L. Wagner, A. S. Chavez, F. F. Gunkelman IV, S. C. Lippert, and J. A. Laundre. 2001. Developmental plasticity allows Betula nana to dominate tundra subjected to an altered environment. Ecology 82:18-32.

Callaghan, T. V., and N. J. Collins. 1981. Life cycles, population dynamics and the growth of tundra plants. Pages 257-284 in L. C. Bliss, O. W. Heal, and J. J. Moore, editors. Tundra ecosystems: a comparative analysis. Cambridge University Press, Cambridge, UK.

Chapin, F. S., and G. R. Shaver. 1981. Changes in soil properties and vegetation following disturbance of Alaskan arctic tundra. Journal of Applied Ecology 18:605-617.

Cressie, N., K. A. Calder, J. S. Clark, J. M. Ver Hoef, and C. K. Wikle. 2009. Accounting for uncertainty in ecological analysis: the strengths and limitations of hierarchical statistical modeling. Ecological Applications 19:553-570.

Densmore, R. 1985. Effects of dynamite and vibrator seismic exploration on visual quality, soils, and vegetations of the Alaskan North Slope. Final report by Envirosphere Company for Geophysical Services, Inc., Anchorage, Alaska, USA.

During, H. J. 1979. Life strategies of bryophytes: a preliminary review. Lindbergia 5:2-18.

Emers, M., and J. C. Jorgenson. 1997. Effects of winter seismic exploration on the vegetation and soil thermal regime of the Arctic National Wildlife Refuge. Pages 443-456 in R. M. M. Crawford, editor. Disturbance and recovery in arctic lands: an ecological perspective. Kluwer Academic Publishers, Dordrecht, The Netherlands.

Emers, M., J. C. Jorgenson, and M. K. Raynolds. 1995. Response of arctic plant communities to winter vehicle disturbance. Canadian Journal of Botany 73:905-919.
Felix, N. A., and M. K. Raynolds. 1989a. The role of snow cover in limiting surface disturbance caused by winter seismic exploration. Arctic 42(2):62-68.

Felix, N. A., and M. K. Raynolds. 1989b. The effects of winter seismic trails on tundra vegetation in northeastern Alaska, U.S.A. Arctic and Alpine Research 21(2):188-202.

Felix, N. A., M. K. Raynolds, J. C. Jorgenson, and K. E. DuBois. 1992. Resistance and resilience of tundra plant communities to disturbance by winter seismic vehicles. Arctic and Alpine Research 24(1):69-77.

Hernandez, H. 1973. Natural plant recolonization of surficial disturbances, Tuktoyaktuk Peninsula Region, Northwest Territories. Canadian Journal of Botany 51:2177-2196.

Jones, B. M., R. Rykhus, Z. Lu, C. D. Arp, and D. J. Selkowitz. 2008. Radar imaging of winter seismic survey activity in the National Petroleum Reserve-Alaska. Polar Record 44(2):1-5.

Jorgenson, J. C., P. E. Joria, T. R. McCabe, B. E. Reitz, M. K. Raynolds, M. Emers, and M. A. Willms. 1994. User's guide for the land-cover map of the coastal plain of the Arctic National Wildlife Refuge. U.S. Fish and Wildlife Service, Anchorage, Alaska, USA.

Jorgenson, M. T., J. E. Roth, M. Emers, S. Schlentner, and J. Mitchell. 2003. Assessment of ecological impacts associated with seismic exploration near the Colville Delta (abstract). Page 7 in Alaska Conference on Reducing the Effects of Oil and Gas Exploration and Production on Alaska's North Slope: Issues, Practices, and Technologies. Idaho National Engineering and Environmental Laboratory, Department of Energy, Boise, Idaho, USA.

Jorgenson, M. T., Y. L. Shur, and E. R. Pullman. 2006. Abrupt increase in permafrost degradation in arctic Alaska. Geophysical Research Letters 33:L02503.

Jorgenson, M. T., Y. L. Shur, and H. J. Walker. 1998. Factors affecting evolution of a permafrost dominated landscape on the Colville river delta, northern Alaska. Proceedings of Seventh International Permafrost Conference. Collection Nordicana 57:523-529.

Kemper, J. T., and S. E. Macdonald. 2009a. Directional change in low-arctic upland tundra plant communities 20-30 years after seismic exploration. Journal of Vegetation Science 20: $557-567$.

Kemper, J. T., and S. E. Macdonald. 2009b. Effects of contemporary winter seismic exploration on low arctic plant communities and permafrost. Arctic, Antarctic, and Alpine Research. 41:228-237.

Kent, M., and P. Coker. 1999. Vegetation description and analysis: a practical approach. John Wiley, London, UK.

Lawson, D. E. 1986. Response of permafrost terrain to disturbance: a synthesis of observations from northern Alaska. Arctic and Alpine Research 18:1-17.

Longton, R. E. 1988. The biology of polar bryophytes and lichens. Cambridge University Press, Cambridge, UK.

Nelson, F. E., O. E. Anisimov, and O. I. Shiklomanov. 2001. Subsidence risk from thawing permafrost. Nature 410:889890.

NRC (National Research Council). 2003. Cumulative environmental effects of oil and gas activities on Alaska's north slope. National Academies Press, Washington, D.C., USA.

Pullman, E. R., M. T. Jorgenson, and Y. Shur. 2007. Thaw settlement in soils of the Arctic Coastal Plain, Alaska. Arctic, Antarctic, and Alpine Research 39(3):468-476.

Radforth, J. R. 1972. Long term effects of summer traffic by tracked vehicles on tundra. ALUR report number 72-73-13. Northern Economic Development Branch, Department of Indian and Northern Affairs, Ottawa, Ontario.

Raynolds, M. K., and N. A. Felix. 1989. Airphoto analysis of winter seismic disturbance in northeastern Alaska. Arctic 42(4):362-367.

Reynolds, P. C. 1982. Some effects of oil and gas exploration activities on tundra vegetation in northern Alaska. Pages 
403-417 in P. J. Rand, editor. Land and water issues related to energy development. Ann Arbor Science, Ann Arbor, Michigan, USA.

Starr, G., S. F. Oberbauer, and L. E. Ahlquist. 2008. The photosynthetic response of Alaska tundra plants to increased season length and soil warming. Arctic, Antarctic, and Alpine Research 40(1):181-191.

USDA. 2009. The PLANTS Database. National Plant Data Center, Baton Rouge, Louisiana, USA. 〈http://plants.usda. gov $\rangle$

Ver Hoef, J. M. 2002. Sampling and geostatistics for spatial data. Ecoscience 9:152-161.

Ver Hoef, J. M., and N. Cressie. 2001. Spatial statistics: analysis of field experiments. Pages 289-307 in S. M. Scheiner and J.
Gurevitch, editors. Design and analysis of ecological experiments. Oxford University Press, Oxford, UK.

Walker, D. A., D. Cate, J. Brown, and C. Racine. 1987. Disturbance and recovery of arctic Alaskan tundra terrain: A review of recent investigations. CRREL Report 87-11. U.S. Army Cold Regions Research and Engineering Laboratories, Hanover, New Hampshire, USA.

Walker, D. A., K. R. Everett, W. Acevedo, L. Gaydos, J. Brown, and P. J. Webber. 1982. Landsat-assisted environmental mapping in the Arctic National Wildlife Refuge, Alaska. CRREL Report 82-27. U.S. Army Cold Regions Research and Engineering Laboratory, Hanover, New Hampshire, USA.

Westman, W. E. 1978. Measuring the inertia and resilience of ecosystems. BioScience 28:705-710.

\section{APPENDIX A}

Fitting the Bayesian hierarchical model (Ecological Archives A020-004-A1).

\section{APPENDIX B}

Sets of graphs showing fitted models of response to three initial levels of winter vehicle disturbance in five tundra vegetation types in arctic Alaska (Ecological Archives A020-004-A2).

\section{APPENDIX C}

Figures and discussion of distribution of disturbance levels on winter seismic trails, monitored over a 25 -year period at 200 random-systematic plots on the trails (Ecological Archives A020-004-A3).

\section{APPENDIX D}

Disturbance and recovery by vegetation types (Ecological Archives A020-004-A4).

\section{APPENDIX E}

Collection of photos depicting seismic lines in 1984 and over time (Ecological Archives A020-004-A5). 
Janet C. Jorgenson, Jay M. Ver Hoef, and M. T. Jorgenson. 2010. Long-term recovery patterns of arctic tundra after winter seismic exploration. Ecological Applications 20:205-221.

Appendix A. Fitting the Bayesian hierarchical model.

For the fully Bayesian specification, distributions for all parameters need to be given. To complete the specification given in the main article, we chose broad priors at this level so that they had little influence on the estimates, except to restrict the parameter space:

$$
\begin{aligned}
& \mu_{\beta 0}, \mu_{\beta 1}, \mu_{\beta 2} \sim N(0,1000), \sigma_{\beta 0}^{2}, \sigma_{\beta 1}^{2}, \sigma_{\beta 2}^{2}, \theta_{s}, \theta_{t}, \theta_{n} \sim G A M(0.001,0.001), \\
& \mu_{\pi 1}, \mu_{\pi 2} \sim \operatorname{UNIF}(0,2), \mu_{\rho} \sim \operatorname{UNIF}(0,200), \text { and } \alpha_{s}, \alpha_{t} \sim \operatorname{UNIF}(0.5,1000) .
\end{aligned}
$$

All parameters were estimated using Markov chain Monte Carlo (MCMC) methods in the statistical package (WinBUGS). For the MCMC, we let the chain "burn in" for 10,000 samples, and then computed the means, standard errors, and percentiles based on the next 100,000 simulations. We started the chain from several different points and obtained very similar results, and examination of the trace of the chain did not reveal any irregularities. Typically, the autocorrelation within the chain for each parameter dropped to near zero well before 30 iterations. For computer storage reasons, we thinned the chain and kept each 100th iteration. We changed prior distributions as a sensitivity analysis and determined that the model was not sensitive to the prior distributions. Besides the parameter estimates, MCMC also allowed us to estimate the uncertainty of functions of the parameters, which we discuss next.

For each plant growth form and for seasonal soil thaw depth, a model was developed that hierarchically nested two factors affecting plant recovery, vegetation type and initial disturbance level. For example, the response curves for soil thaw depths in one vegetation type has only eight plot pairs, but the model 'borrows strength' from the next higher level in the model, which includes all 49 plot pairs (Fig. A1). The model's algorithms allow the response curves for each vegetation type and each initial disturbance level to diverge from the global curve for all 49 plots by amounts that vary depending on sample size and within-type variability. Figure A1 also demonstrates a method to estimate time to recovery. For discussion purposes, we chose to define recovery as a return to an absolute difference of +5 or $-5 \%$ cover for plant growth forms and +5 or $-5 \mathrm{~cm}$ for thaw depth. The credibility interval on the estimate is given by the solid black line, which runs horizontally between the lower bound to the upper bound of the curve. Here the credibility interval is shown only for high-level disturbance. The same procedure can be applied to other recovery thresholds. 


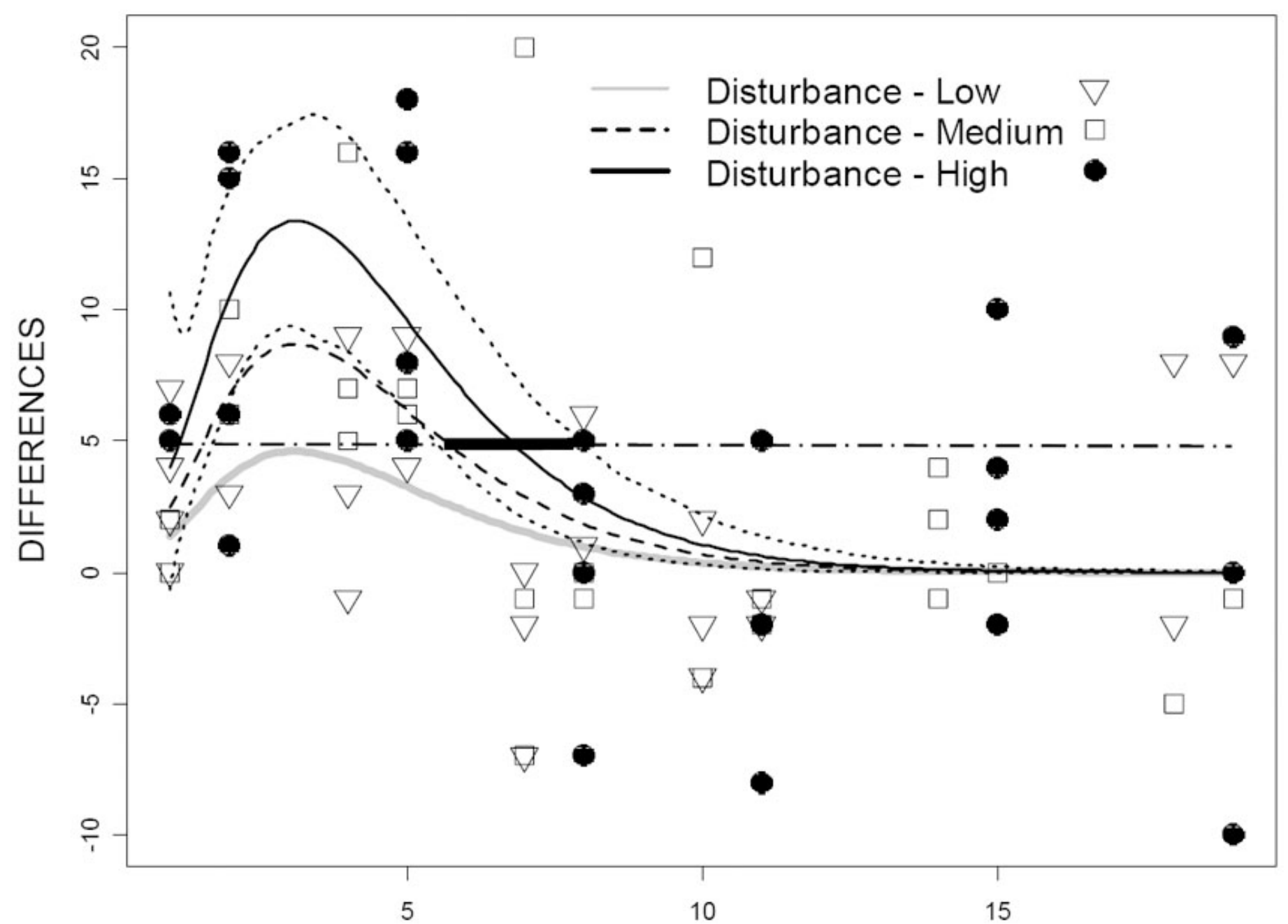

YEAR FROM INITIAL DISTURBANCE

FIG. A1. Example of fitted model for soil thaw depths in Sedge-Willow Tundra only. Each data point is the absolute difference between soil thaw depths $(\mathrm{cm})$ at one plot pair (disturbed, reference). The short-dashed line is the $95 \%$ credibility envelope of the fitted model for the highest level of initial disturbance. Credibility envelopes for medium and low level disturbance are not shown. The estimated time to recovery is the time (here, approximately year 7 for high disturbance) where the curve crosses the $+5 \%$ difference line (dash-dot). The credibility interval on that estimate is given by the thick black line (here, approximately $5.5-8.5$ years), which runs horizontally between the lower bound to the upper bound of the curve. 
Janet C. Jorgenson, Jay M. Ver Hoef, and M. T. Jorgenson. 2010. Long-term recovery patterns of arctic tundra after winter seismic exploration. Ecological Applications 20:205-221.

Appendix B. Six sets of graphs show fitted models of response of graminoids, deciduous shrubs, forbs and horsetails, lichens, bryophytes, and evergreen shrubs to three initial levels of winter vehicle disturbance in five tundra vegetation types in arctic Alaska. Differences are percent cover in disturbed plot minus percent cover in adjacent reference plot. The short-dashed line is the $95 \%$ credibility envelope of the fitted model for the highest level of initial disturbance. The variance components are $\theta_{\mathrm{t}}($ temporal $), \theta_{\mathrm{S}}($ spatial $)$, and $\theta_{\mathrm{n}}(\mathrm{nugget})$. 

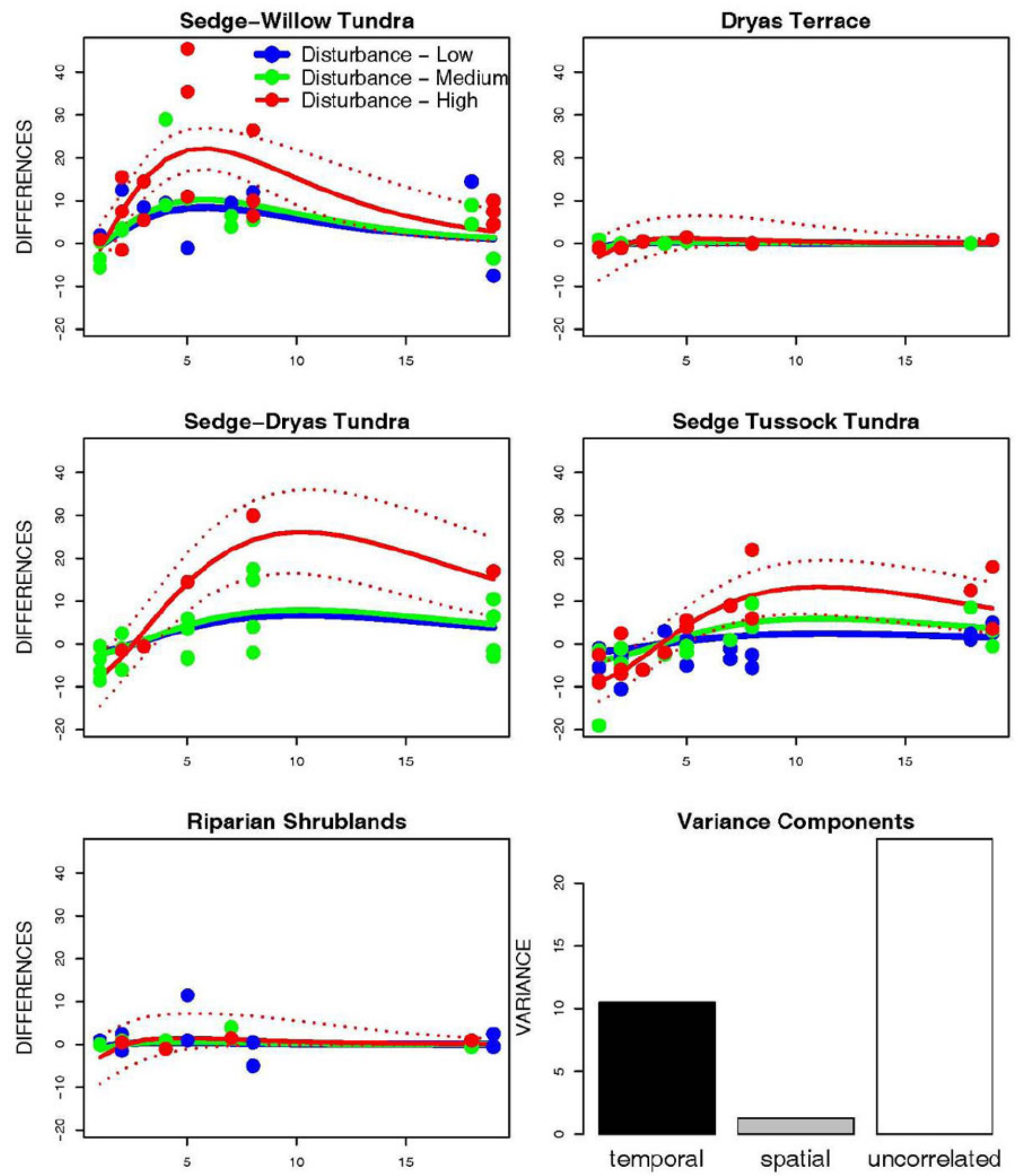

YEAR FROM INITIAL DISTURBANCE 
Sedge-Willow Tundra
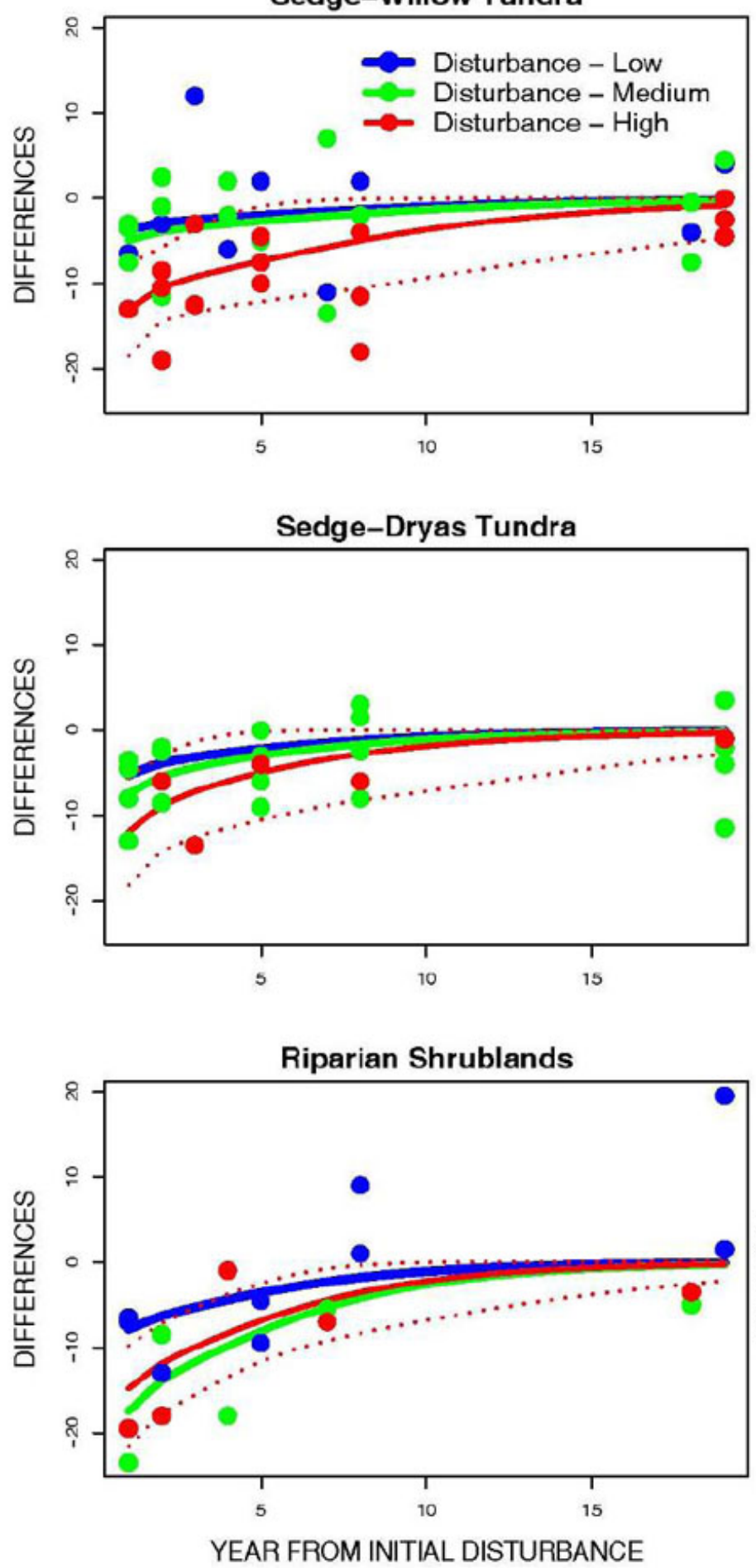

Dryas Terrace

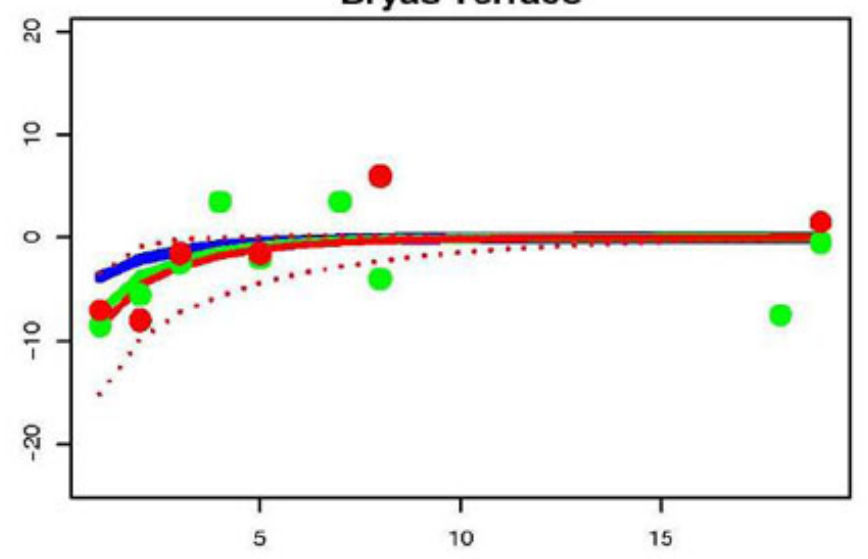

Sedge Tussock Tundra

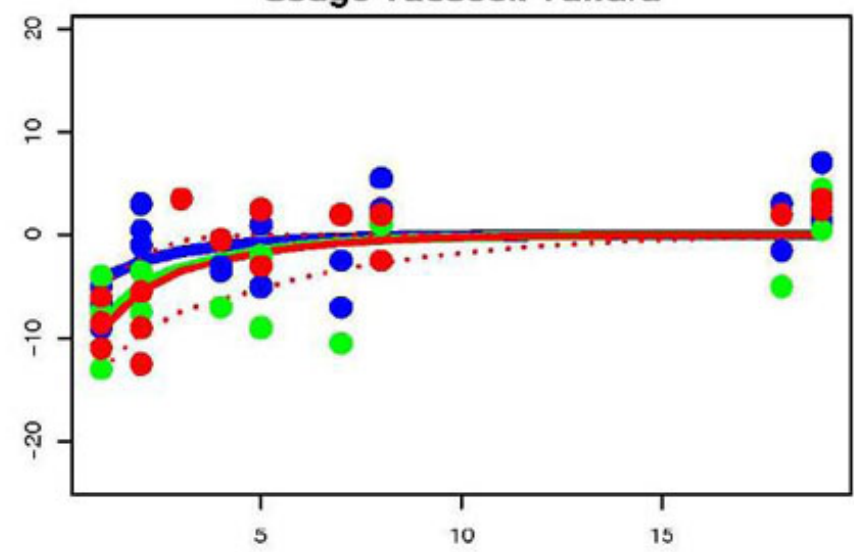

Variance Components

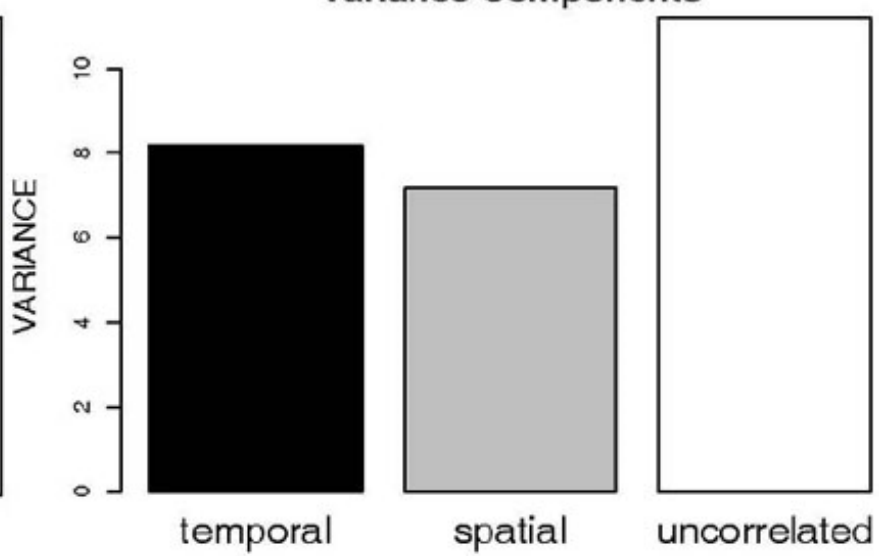



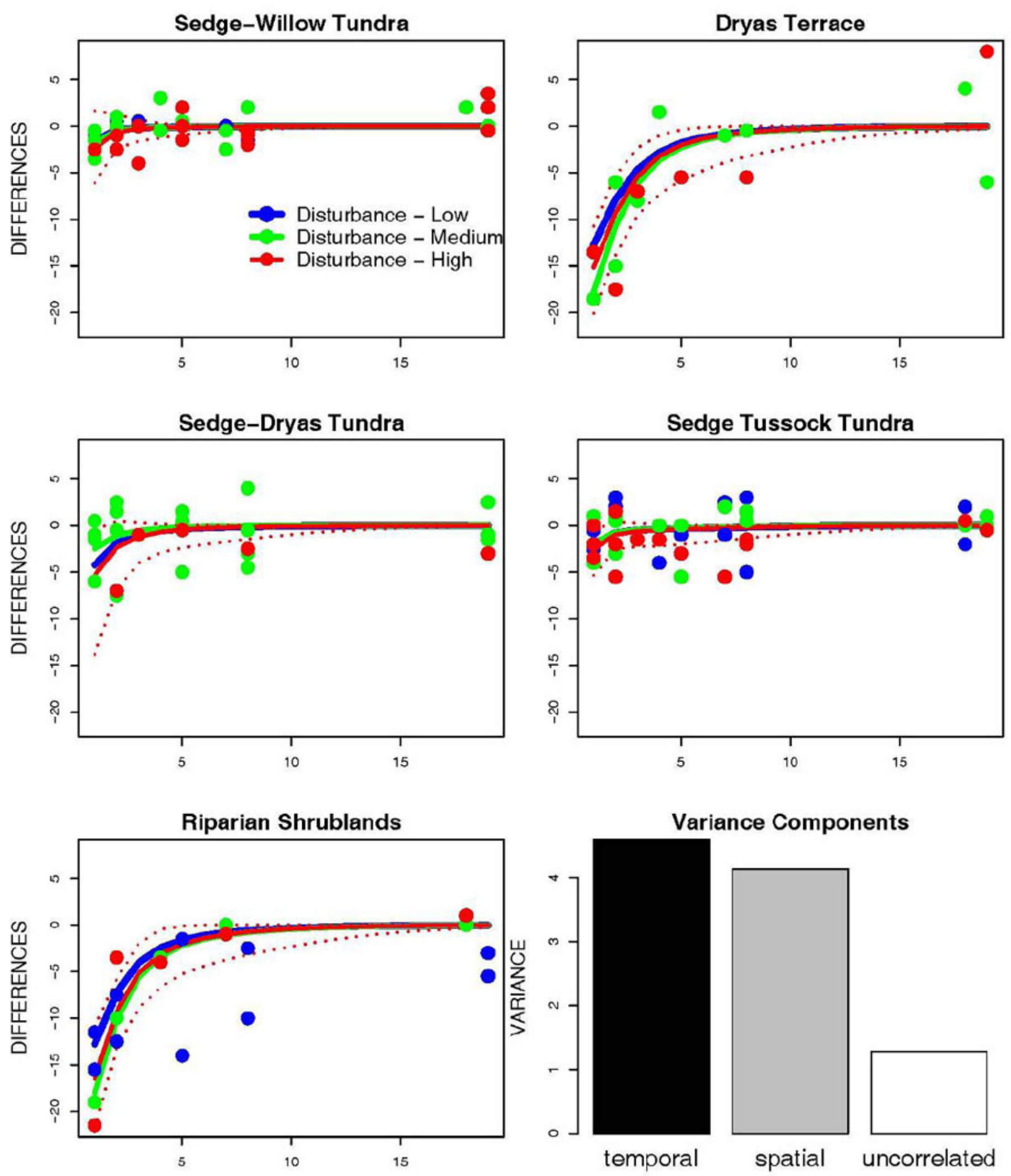

YEAR FROM INITIAL DISTURBANCE 

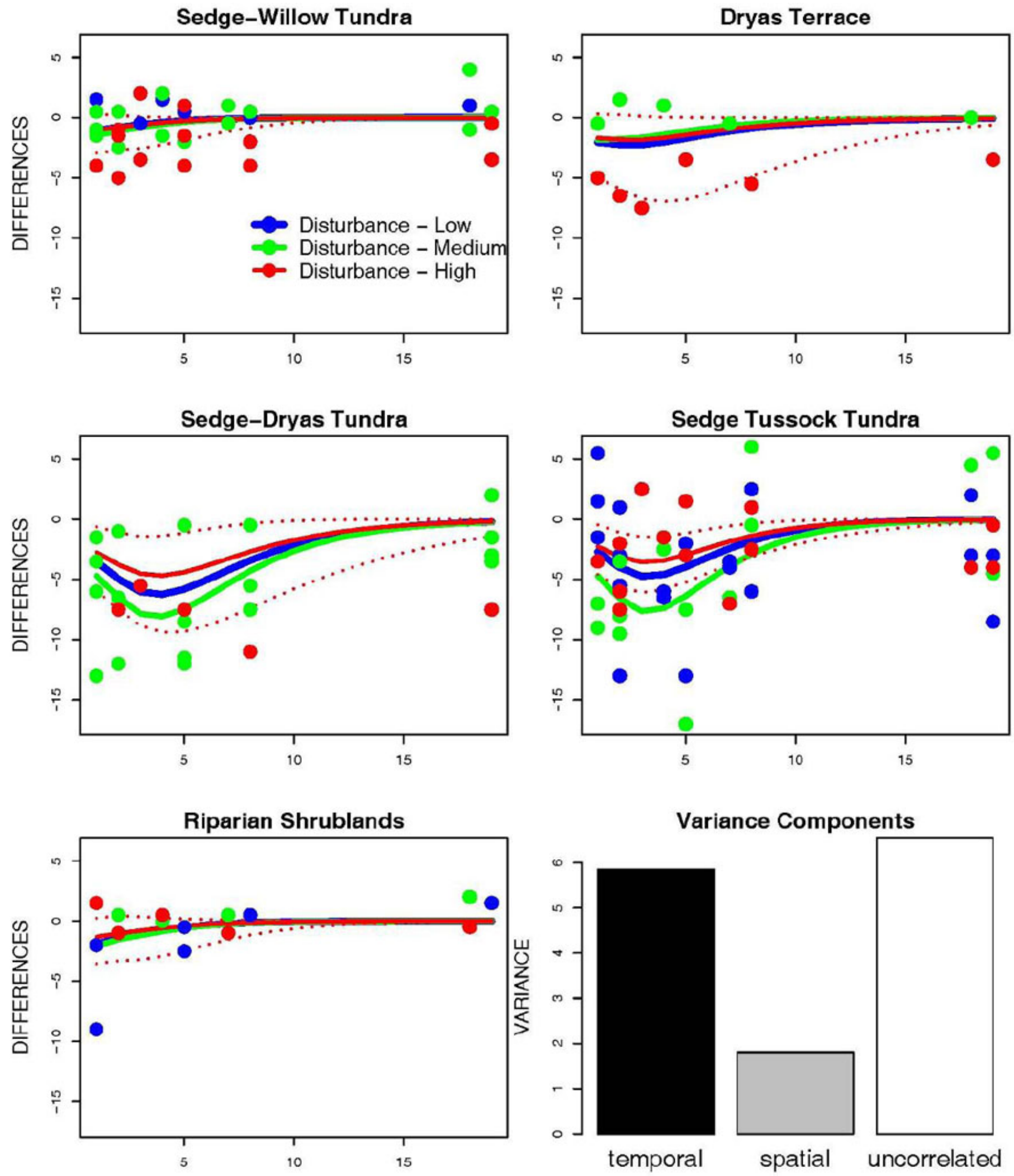

YEAR FROM INITIAL DISTURBANCE 

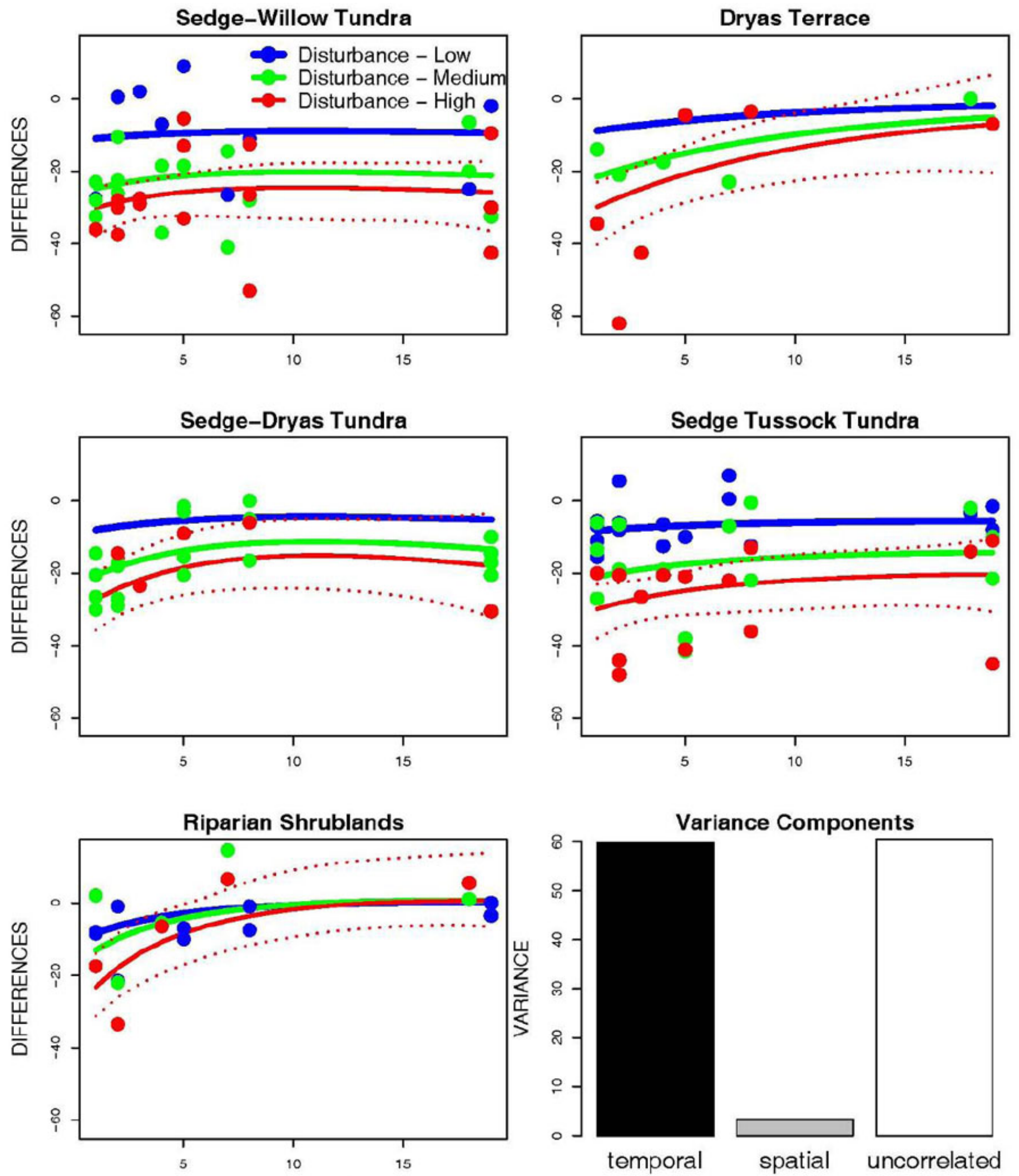

YEAR FROM INITIAL DISTURBANCE 

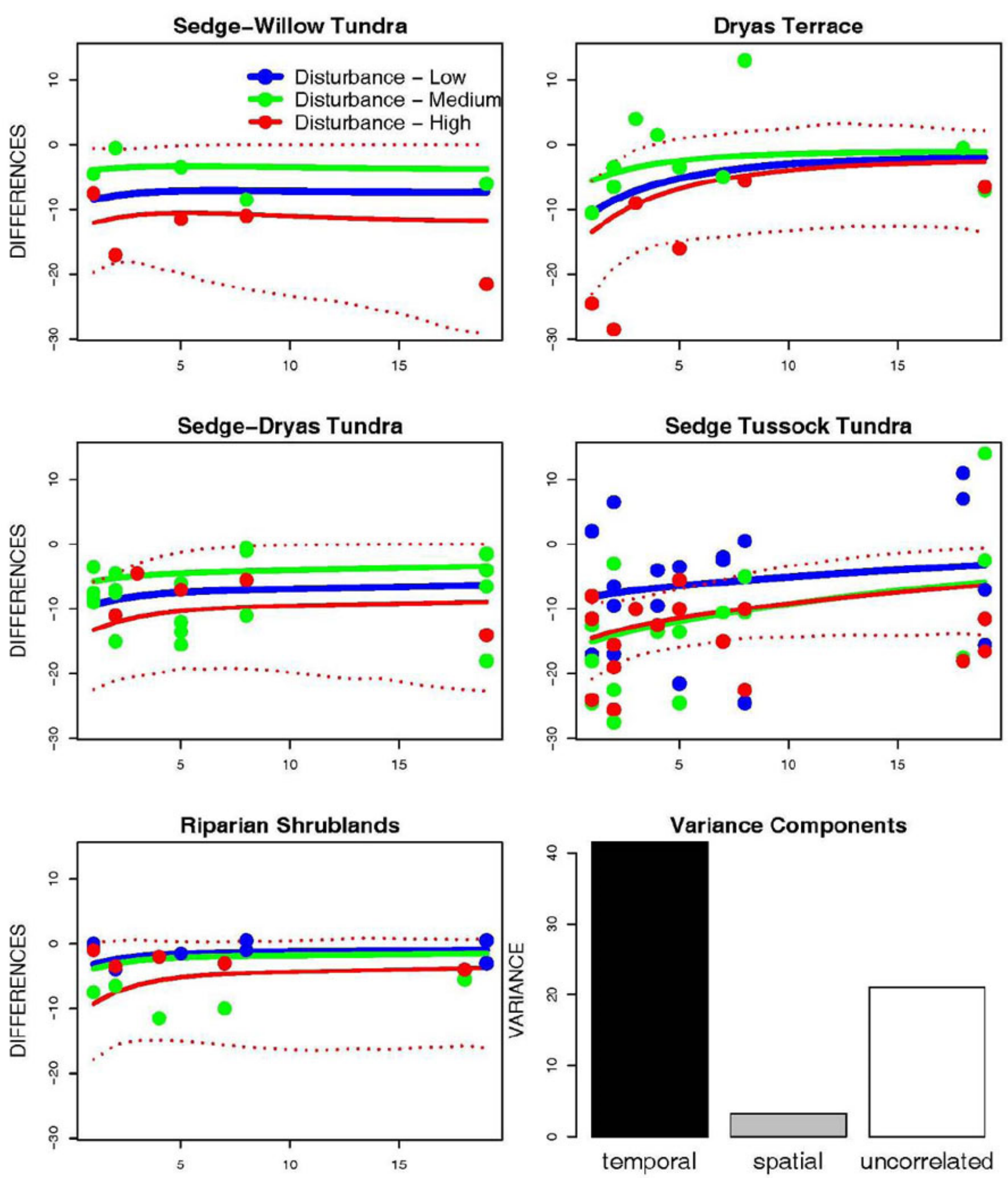

YEAR FROM INITIAL DISTURBANCE 


\section{Janet C. Jorgenson, Jay M. Ver Hoef, and M. T. Jorgenson. 2010. Long-term recovery patterns of arctic tundra after winter seismic exploration. Ecological Applications 20:205-221.}

Appendix C. Figures and discussion of distribution of disturbance levels on winter seismic trails, monitored over a 25 year period at 200 random-systematic plots on the trails.

\section{Introduction}

Seismic exploration was conducted on the coastal plain of the Arctic National Wildlife Refuge, Alaska, during the winters of 1984 and 1985. U.S. Fish and Wildlife Service initiated a monitoring program in 1984 to document vegetation and soil disturbance and natural recovery. This appendix presents results from one part of the monitoring program, a sample of 200 random-systematic plots on the trails that were visited over a 25 year period and rated for amount of disturbance.

\section{Methods}

Color-infrared aerial photographs (1:6000-scale) were taken of 20\% of the trails in 1985 and 1988 and disturbance levels were photointerpreted at 4914 systematic plots (Raynolds and Felix 1989). Next, a two-stage cluster sample was used to randomly choose 200 of the plots to monitor in the field. Twenty $3-\mathrm{km}$ transects, each consisting of ten $18-\mathrm{m}$ diameter circular plots spaced 300-m apart, were randomly selected. A four-level system for rating vehicle disturbance based on vegetation and soil changes was used (Table 2 in main paper). Ratings were assigned initially in 1985 by photo-interpretation and subsequently by field evaluations in 1989, 1993, 1998, 2002, 2005, and 2009. All plots were visited in 1989. From 1993 to 2009, plots rated as undisturbed in a previous year were assumed to remain undisturbed thereafter and were not revisited.

Disturbance and recovery were summarized by trail type (seismic line or camp move trail) and vegetation types, which included Wet Sedge Tundra, Moist Sedge-Willow Tundra, Moist Sedge-Dryas Tundra, Moist Sedge-Tussock tundra, Shrub Tundra on high-centered polygons, Riparian Shrublands, and Partially Vegetated (Table 1 in main paper). The vegetation type Dryas Terrace was not represented in the 200 plot sample, but data were available from the larger photo-interpreted sample. Ten randomly selected Dryas Terrace plots were photointerpreted in 1985 and visited in 1988 and 2007 to assess recovery.

\section{Results and Discussion}

Snow was usually less than $30 \mathrm{~cm}$ deep and did not provide complete protection from vehicle damage. The following summer most trails had at least some scuffing of vegetation and deeper summer-thawed soil. The greatest damage was destruction of shrubs and sedge tussocks, scraping of ground cover to bare soil, and standing water on trails. Tussock Tundra, Shrub Tundra, and Dryas Terrace were the vegetation types with the highest initial disturbance (Fig. C1). About one half of these plots had medium and high-level disturbance in 1985.

Sedge-Dryas Tundra and Sedge-Willow Tundra were intermediate in disturbance levels, with medium- and high-level disturbance found at about one third of the plots. Medium- and high-level disturbance was absent in Riparian Shrublands, which collect deep snow, and occurred in $<10 \%$ of plots in Wet Sedge Tundra. Partially Vegetated areas had negligible damage.

Recovery was rapid in the first decade as the percentage of disturbed plots decreased from $79 \%$ in 1985 , to $48 \%$ in 1989 , and to $11 \%$ in 1993. Recovery was slower after 1993. Five percent of plots were still disturbed in 2009. For points that initially had low level disturbance, recovery was rapid. Twenty-three percent of all points had medium to high levels of disturbance in 1985 and these recovered more slowly.

Tussock Tundra and Sedge-Willow Tundra plots recovered well except for a few that remained wetter or subsided into troughs, causing a change in vegetation type. Sedge-Dryas Tundra frequently subsided after medium to highly initial disturbance, with $19 \%$ of plots still disturbed after 25 years. These sites had changed vegetation due to wetter conditions. Shrub Tundra and Dryas Terrace had some low level disturbance remaining in 2007-2009, mainly patchy subsidence and vehicle ruts that did not subside. Plant community composition changes at these sites were subtle, mainly decreased cover of shrubs.

Camp-move trails were made by vehicles with higher ground pressure than seismic lines and had more initial damage and slower recovery (Fig. C2). By 1989, 32\% of seismic trails were still disturbed compared to $64 \%$ of camp trails, including $41 \%$ at medium- and high-level disturbance. By 2009, all seismic trail plots had recovered to a negligible disturbance level, whereas $9 \%$ of the camp trail plots were still disturbed and one half of those had medium and high-level disturbance. Overall, $5 \%$ of plots were still disturbed in 2005 . This translates to $200 \mathrm{~km}$ of disturbed trail, out of the original $4000 \mathrm{~km}$ of trails.

Previous studies of winter seismic vehicle disturbance in the Arctic predicted only short-term and mostly aesthetic impacts. Long-term monitoring showed that most of the disturbance disappeared gradually, but that impacts to tundra vegetation persisted on a small percentage of the trails up to 25 years after disturbance. 
Wet Graminoid $(n=44)$

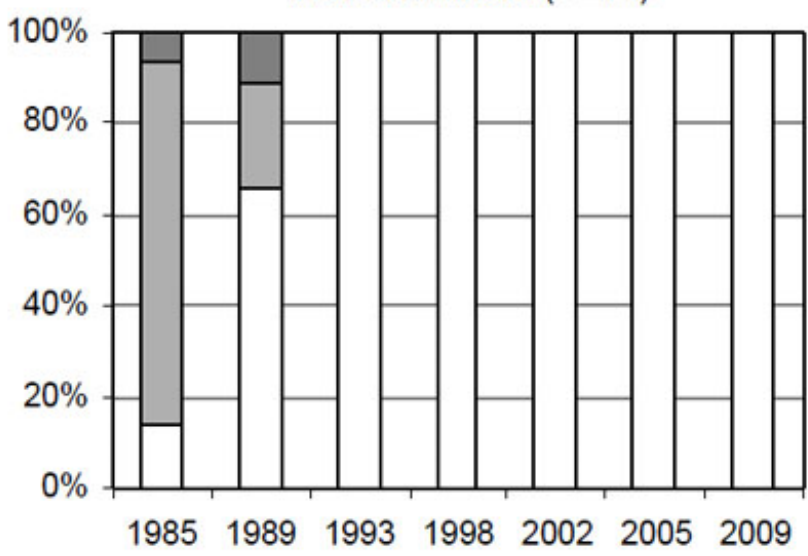

Moist Sedge-Willow $(n=70)$

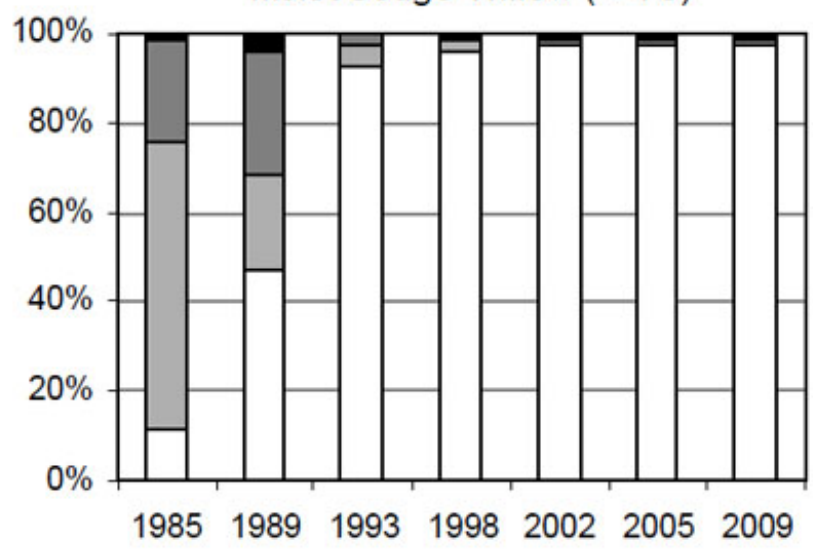

Riparian Shrub $(n=5)$

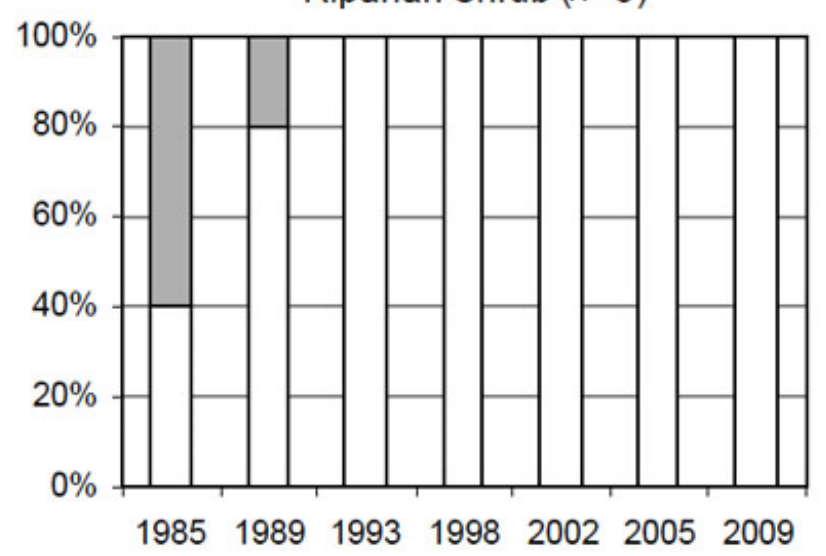

Dryas Terrace $(n=10)$

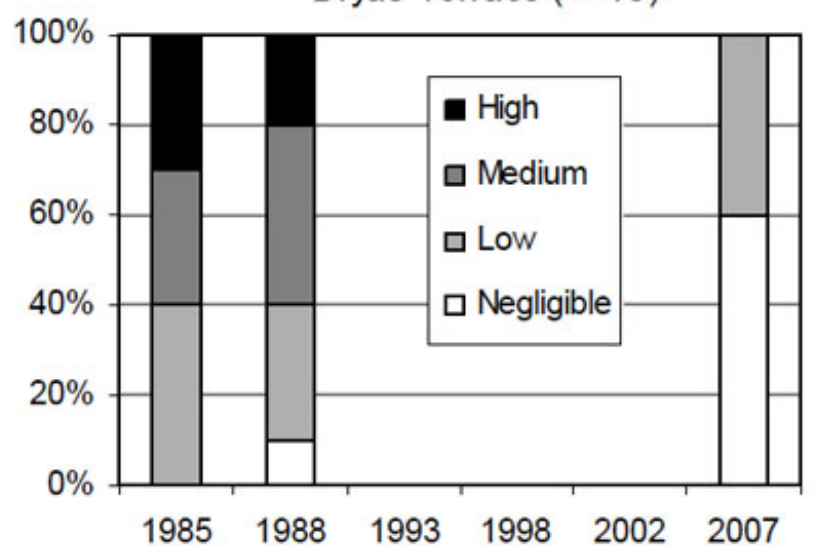

Moist Sedge-Dryas $(n=16)$

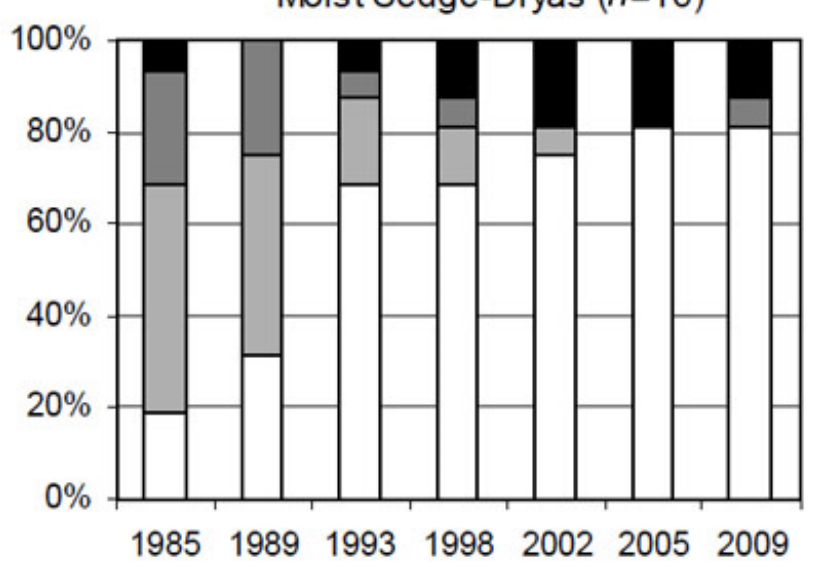

Tussock Tundra $(n=32)$

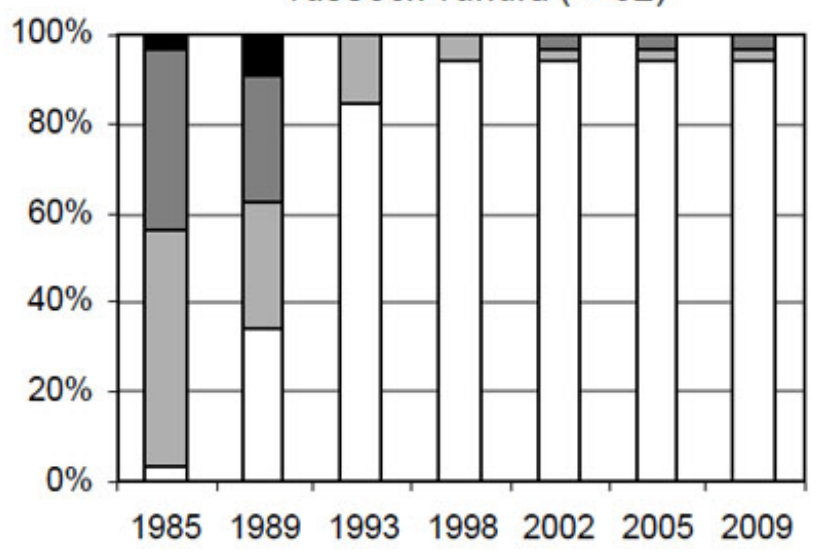

Shrub Tundra $(n=12)$

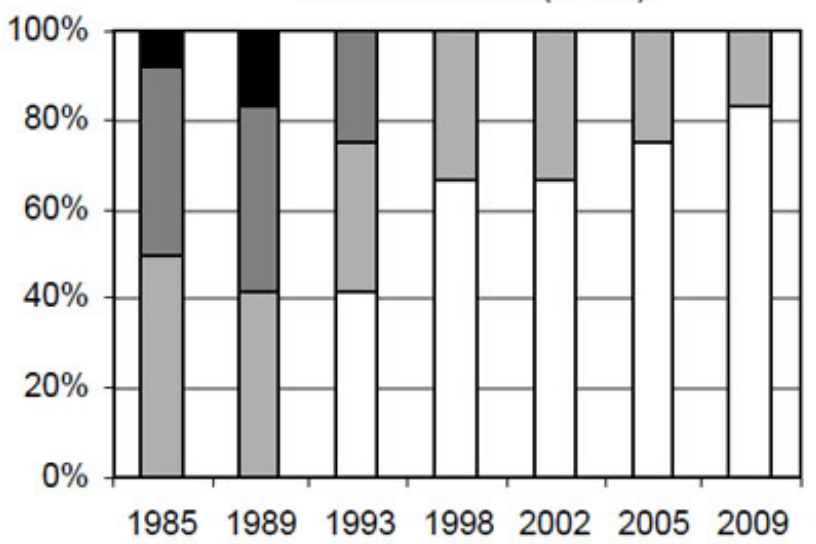


FIG. C1. Recovery of vehicle trails on different tundra vegetation types after winter seismic exploration in 1984 and 1985. Ratings were photo-interpreted on color-infrared aerial photographs in 1985. All other years were rated in the field. Twenty-one plots on unvegetated areas or partially vegetated gravel bars had negligible disturbance in all years and are not shown.
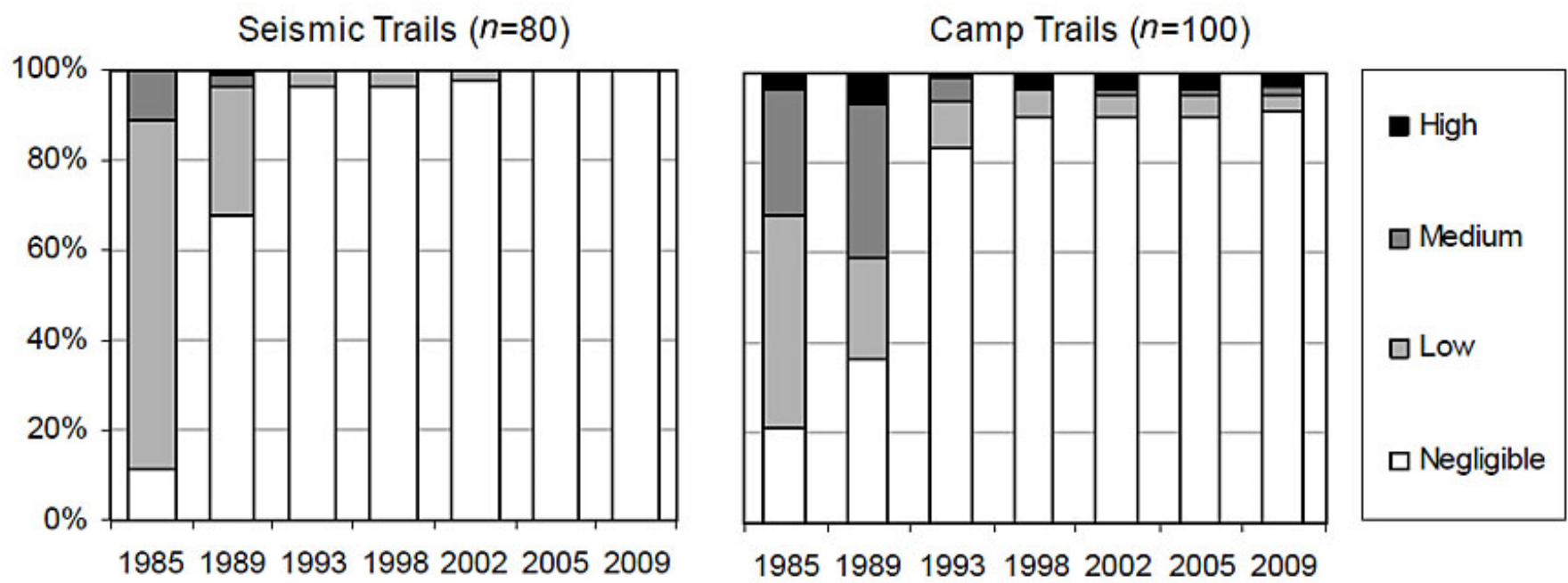

FIG. C2. Recovery on seismic line trails vs. camp move trails. Ratings were photo-interpreted on color-infrared aerial photographs in 1985. All other years were rated in the field. Twenty plots with overlapping seismic lines and camp move trails are not shown.

\section{LITERATURE CITED}

Raynolds, M. K., and N. A. Felix. 1989. Airphoto analysis of winter seismic disturbance in northeastern Alaska. Arctic 42(4):362-367. 


\section{Ecological Archives A020-004-A4}

\section{Janet C. Jorgenson, Jay M. Ver Hoef, and M. T. Jorgenson. 2010. Long-term recovery patterns of arctic tundra after winter seismic exploration. Ecological Applications}

\section{0:205-221.}

\section{Appendix D. Disturbance and recovery by vegetation types.}

Evaluating the recovery among differing vegetation types provides useful information for managing seismic exploration programs to minimize long-term damage. In this Appendix we summarize study results for each of the seven major vegetation types in the study area.

Wet Sedge Tundra incurred little vegetation damage from traffic and recovered rapidly because of the dominance of the sedge growth form. Trails were very visible the first summer after exploration because dead sedge leaves were compressed to the soil surface, making green leaves more visible (the 'green trail' effect), and because leaf production and nutrient status increased (Emers et al. 1994). Recovery was aided by the lack of evident thaw settlement, probably due to the low excess segregated ice contents associated with thick peat horizons of Wet Sedge Tundra. Also, the saturated soil in wet sites freezes solid in winter, so winter vehicle traffic does not cause soil displacement. Although we had insufficient samples to analyze the recovery of Wet Sedge Tundra separately, a companion study that tracked disturbance at random plots found that $93 \%$ of Wet Sedge plots had low or no initial disturbance (Appendix C). Wet Sedge Tundra and Riparian Shrublands were the only types in which all plots recovered to level zero disturbance rating in the first decade.

Most trails in Sedge-Willow Tundra exhibited the transient green trail effect, but had low initial disturbance and recovered well by 2002. However, medium or high levels of initial disturbance often caused soil subsidence and vegetation on the trails converted to Wet Sedge Tundra. Some of these trails remained highly visible viewed from the air up to 24 years after disturbance and cannot be expected to return to the original vegetation for many more decades. Without subsidence, the dominant sedges and deciduous shrubs recovered to near reference levels within the first decade, although the bryophyte understory showed little recovery.

Trails on Tussock Tundra had greater initial impacts to graminoid cover than other vegetation types, because of damage to raised tussocks of Eriophorum vaginatum. Trails recovered well if initial disturbance was low, with good vegetative regrowth of damaged tussocks. On trails with higher levels of disturbance, most tussocks were smashed and some trails subsided. Sedge cover increased above reference levels, mainly due to an increase for Eriophorum angustifolium, causing some trails to remain visible from the air after two decades. Deciduous shrubs generally recovered to pre-disturbance conditions in the first decade. Evergreen shrubs and bryophytes were highly impacted initially and usually did not recover.

Trails on Shrub Tundra commonly had ruts, bare ground, and severe shrub damage. Evergreen shrubs were very slow to recover. Some had not recovered after two decades, although trail subsidence was less visible than in the other types, due to many natural troughs. Sections of shrub-dominated high centered polygons, tundra areas raised by accumulation of ground ice, sometimes subsided into adjacent troughs as the ice melted and were converted to sedge-dominated trough vegetation.

At many Sedge-Dryas Tundra plots disturbance increased over time, because of surface subsidence of 20-50 $\mathrm{cm}$. Subsidence of up to $1 \mathrm{~m}$ was occasionally seen where trails crossed hill slopes, intercepting down-slope flow of water. Vegetation recovery was poorer than in other types even where subsidence was not detectible. Graminoid cover increased above reference levels and other plant growth forms did not recover after 18 years. Sedge-Dryas Tundra plots recovered less than Tussock Tundra, Shrub Tundra, and Dryas Terrace, even 
though those types had higher initial disturbance levels. Few other studies have documented the poor resilience of this vegetation type to damage, perhaps because impacts are seldom monitored longer than 2-3 years. BLM (unpublished data) found that Dwarf Shrub Tundra, which includes this type and Dryas Terrace, recovered the least of any type and was the only type with high-level disturbance remaining six years after exploration. One quarter of their Dwarf Shrub plots had medium or high level disturbance after six years. Moskalenko (1984) reported that vegetation recovery up to 10 years after very high level disturbances in Siberian gas fields was poorer in this type than all other vegetation types studied and concluded that "total restoration of the vegetation can never be expected". She cited several attributes of this type of site that make recovery difficult, including poor anchoring of soil by a naturally discontinuous vegetative mat, naturally mixed soil horizons due to frost action, and abrupt changes in soil moisture after disturbance.

Riparian sites had good vegetation recovery, even at plots with extreme initial damage, because the ice-poor gravel substrate did not subside. Dryas terraces normally have thin snow cover and were usually severely damaged by winter vehicle traffic. They have a thin layer of organic soil over well-drained fluvial gravels which allow the organic mat and plant roots to be easily damaged. This and other studies predicted long-term damage. The prostrate shrubs, mosses, and lichens were easily damaged but recovered better than in most other vegetation types, because there was no subsidence when thawed and conditions for plant growth did not change. The dominant plant, the evergreen shrub Dryas integrifolia, is considered highly sensitive to disturbance and was initially the most impacted shrub in this study. Recovery after 18 years was not complete, but better than predicted by early reports from this study and other shorter-term studies.

Riparian shrublands had less initial damage than Dryas terraces because the taller willows collected wind-blown snow that usually protected the ground cover. Willows were badly broken but they grew vigorously after disturbance, as would be expected of plants adapted to herbivory. Riparian areas are considered sensitive to vehicle disturbance and are frequently avoided by seismic crews, because the smashed willows are unsightly the following summer. BLM (unpublished data) reported that Riparian Shrublands were the most disturbed type after winter seismic exploration and remained more disturbed after six years than most non-riparian types. This study shows that non-riparian types are actually more susceptible to long-term damage.

\section{LITERATURE CITED}

Emers, M., J. C. Jorgenson, and M. K. Raynolds. 1995. Response of Arctic plant communities to winter vehicle disturbance. Canadian Journal of Botany. 73:905-919.

Moskalenko, N. G. 1984. Predictions as to the recovery of the vegetation cover destroyed by human activities in the north of western Siberia. Polar Geography and Geology 4:147-154. 


\section{Ecological Archives A020-004-A5}

Janet C. Jorgenson, Jay M. Ver Hoef, and M. T. Jorgenson. 2010. Long-term recovery patterns of arctic tundra after winter seismic exploration. Ecological Applications 20:205-221.

Appendix E. Collection of photos depicting seismic lines in 1984 and over time.

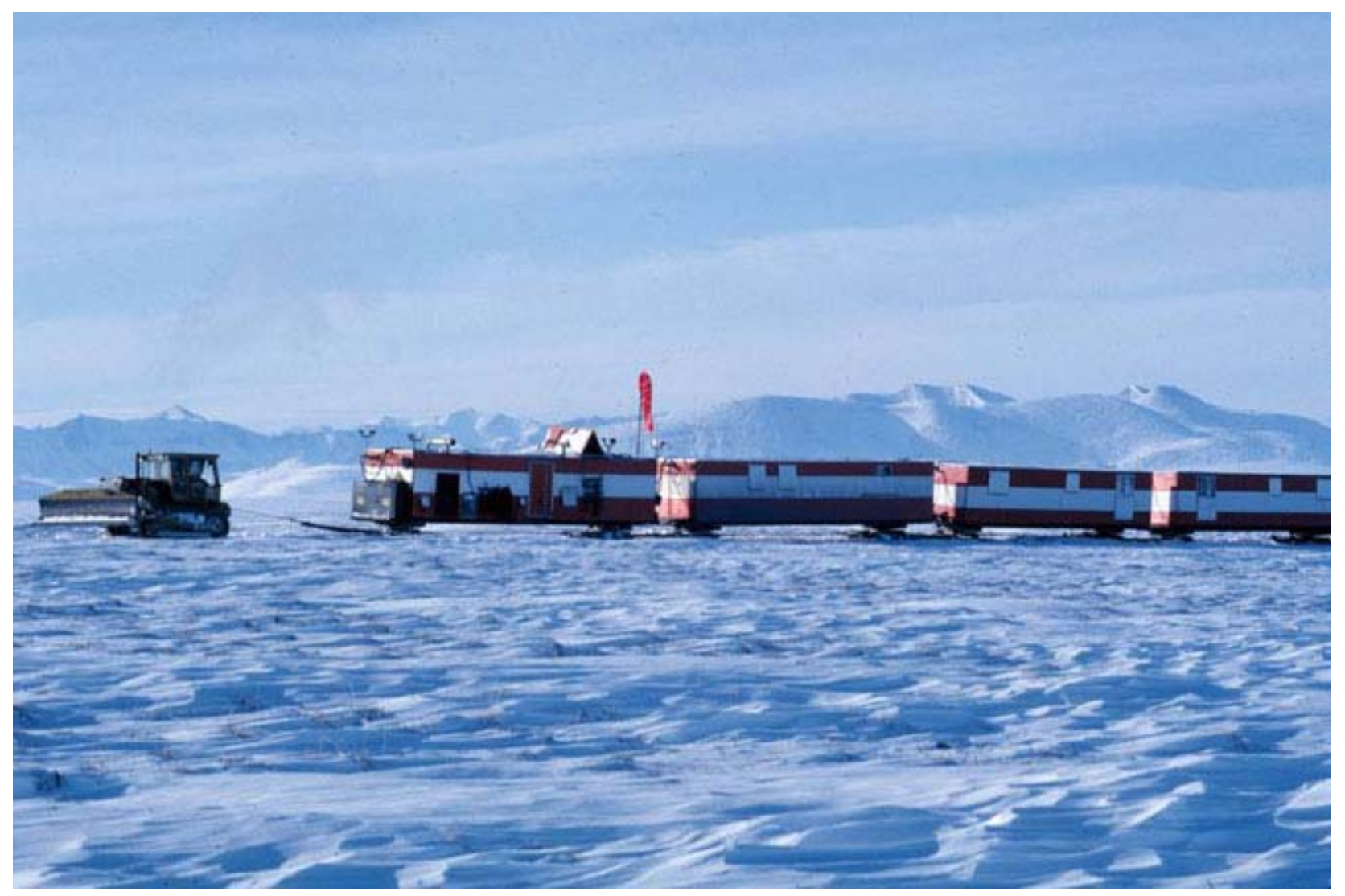

Pното E1. D-7 caterpillar tractor pulling ski-mounted camp trailers during seismic exploration in February 1984. 


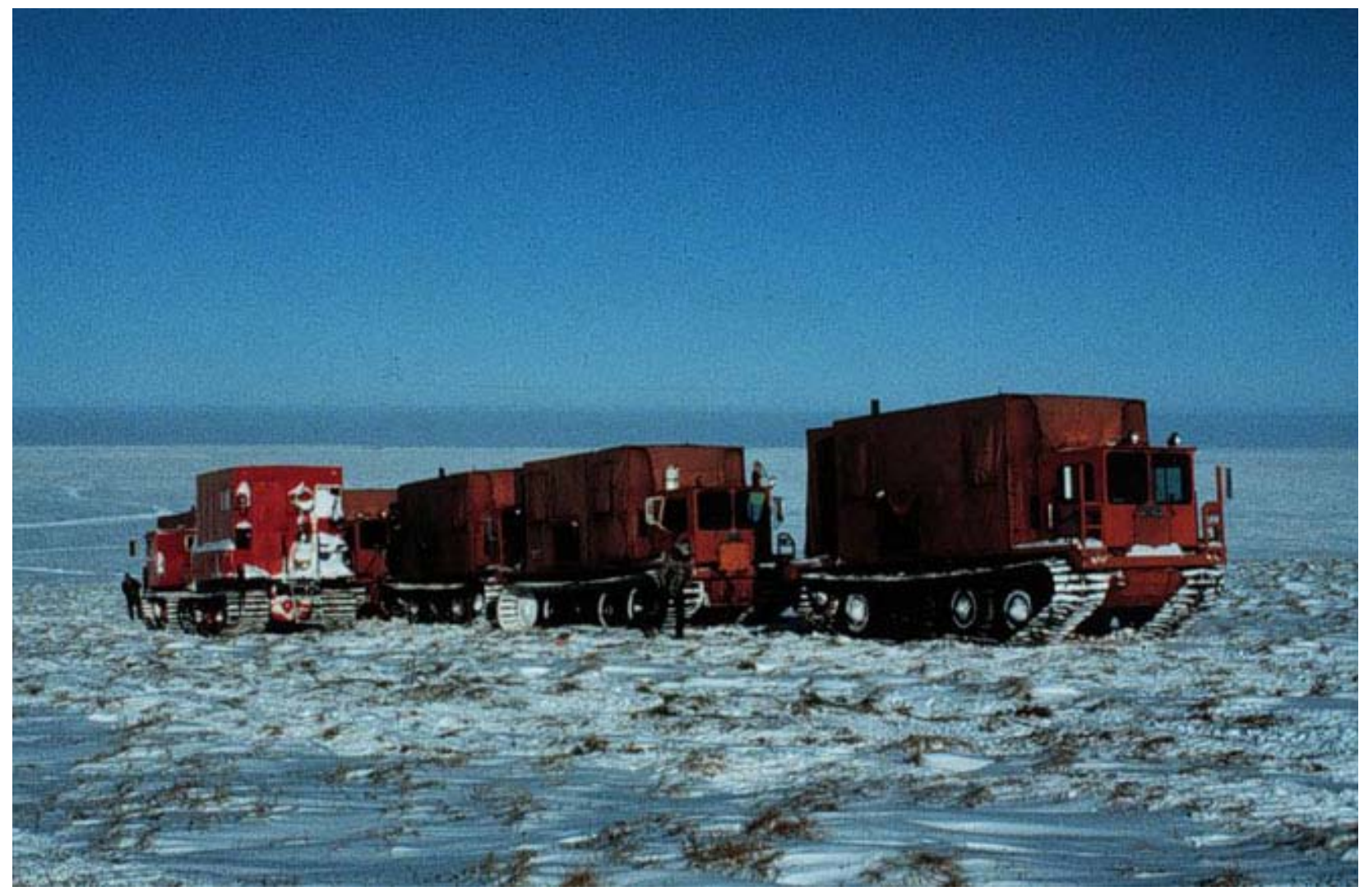

Рното E2. Seismic vibrator units in winter of 1985. 


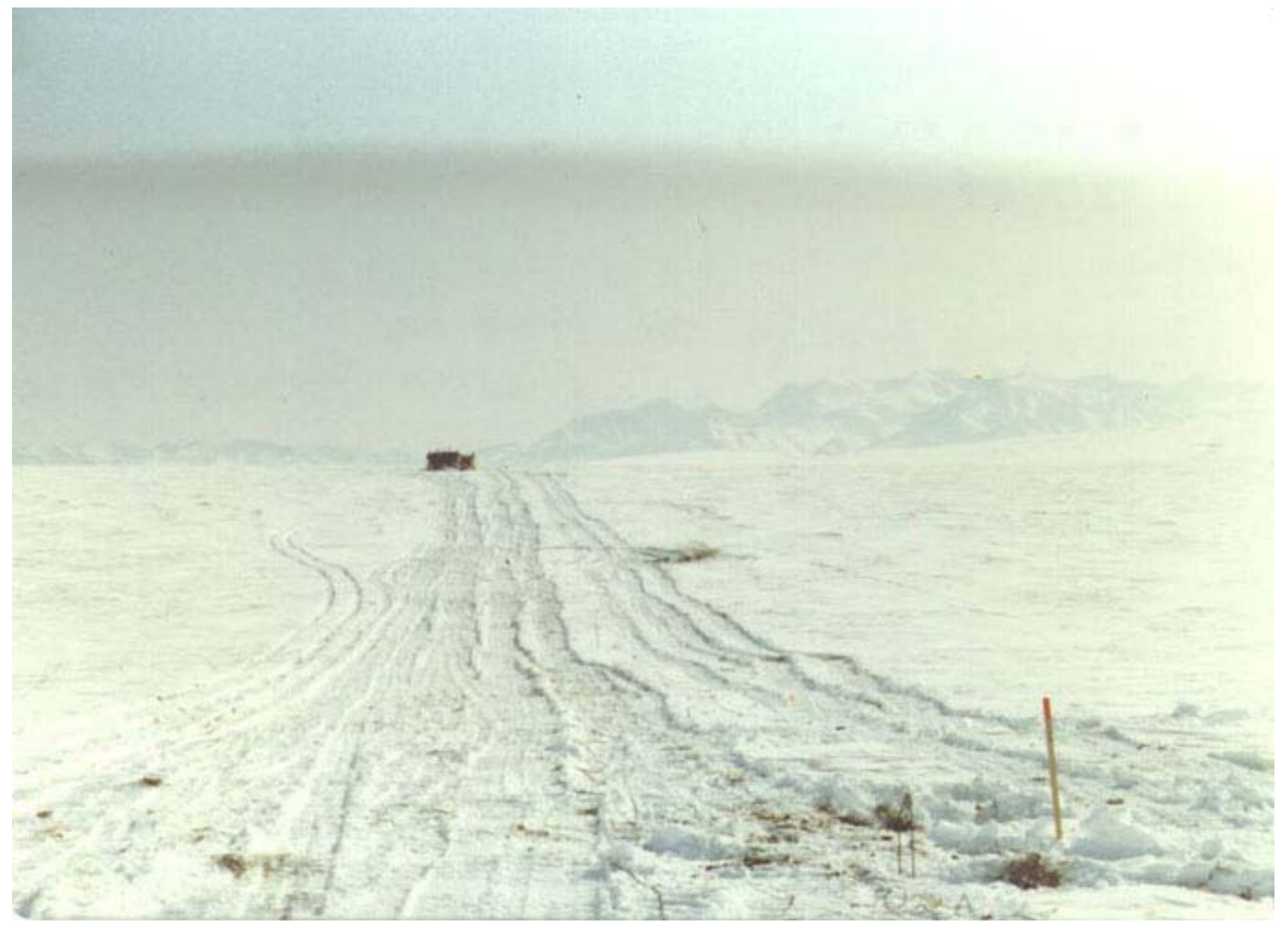

Pното E3. Seismic line in April 1984. 


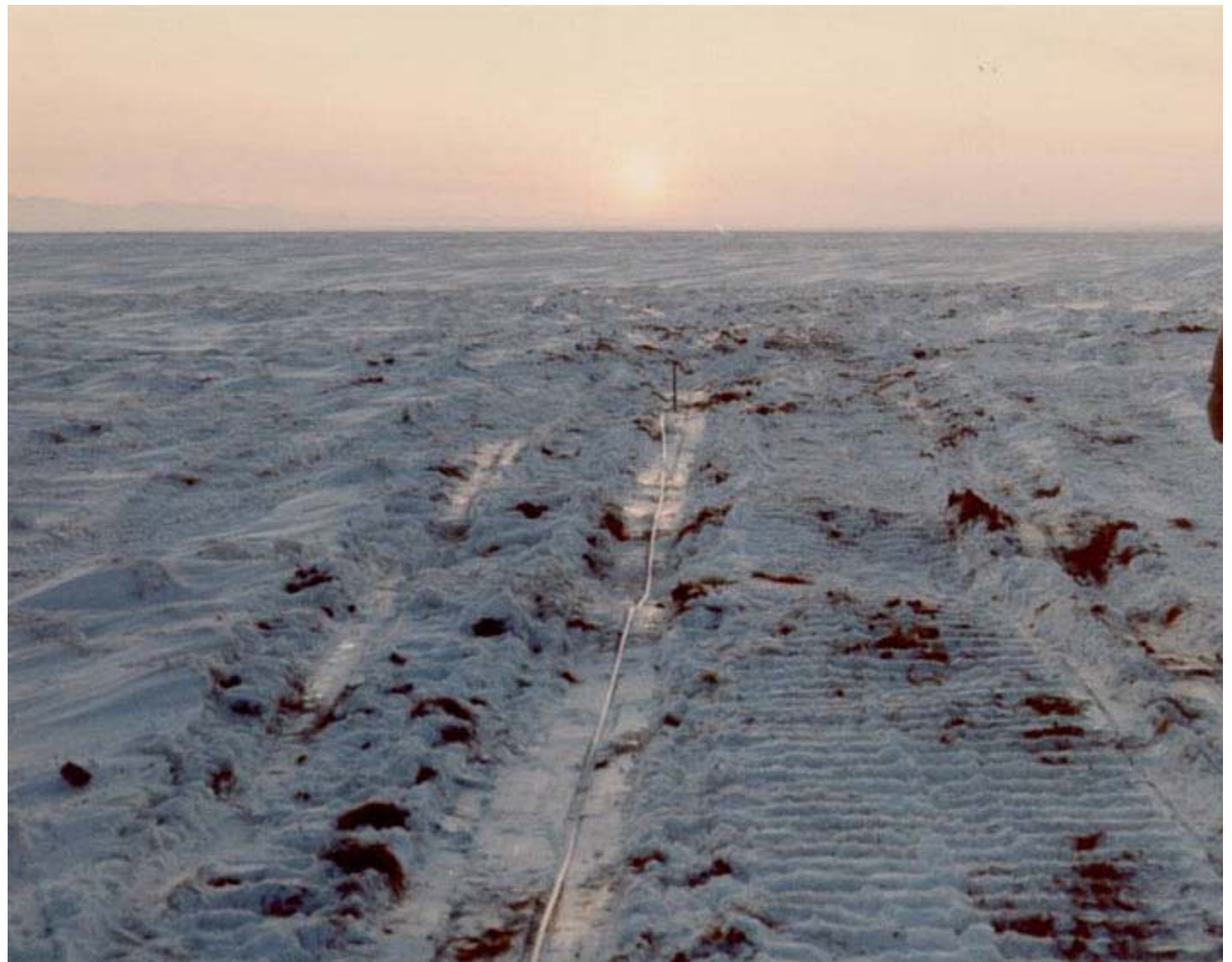

Pното E4. Camp-move trail made on Sedge-Dryas Tundra in March 1984. The adjacent reference plot had 1 in 1985 and trail had become a shallow trough by 2002. 


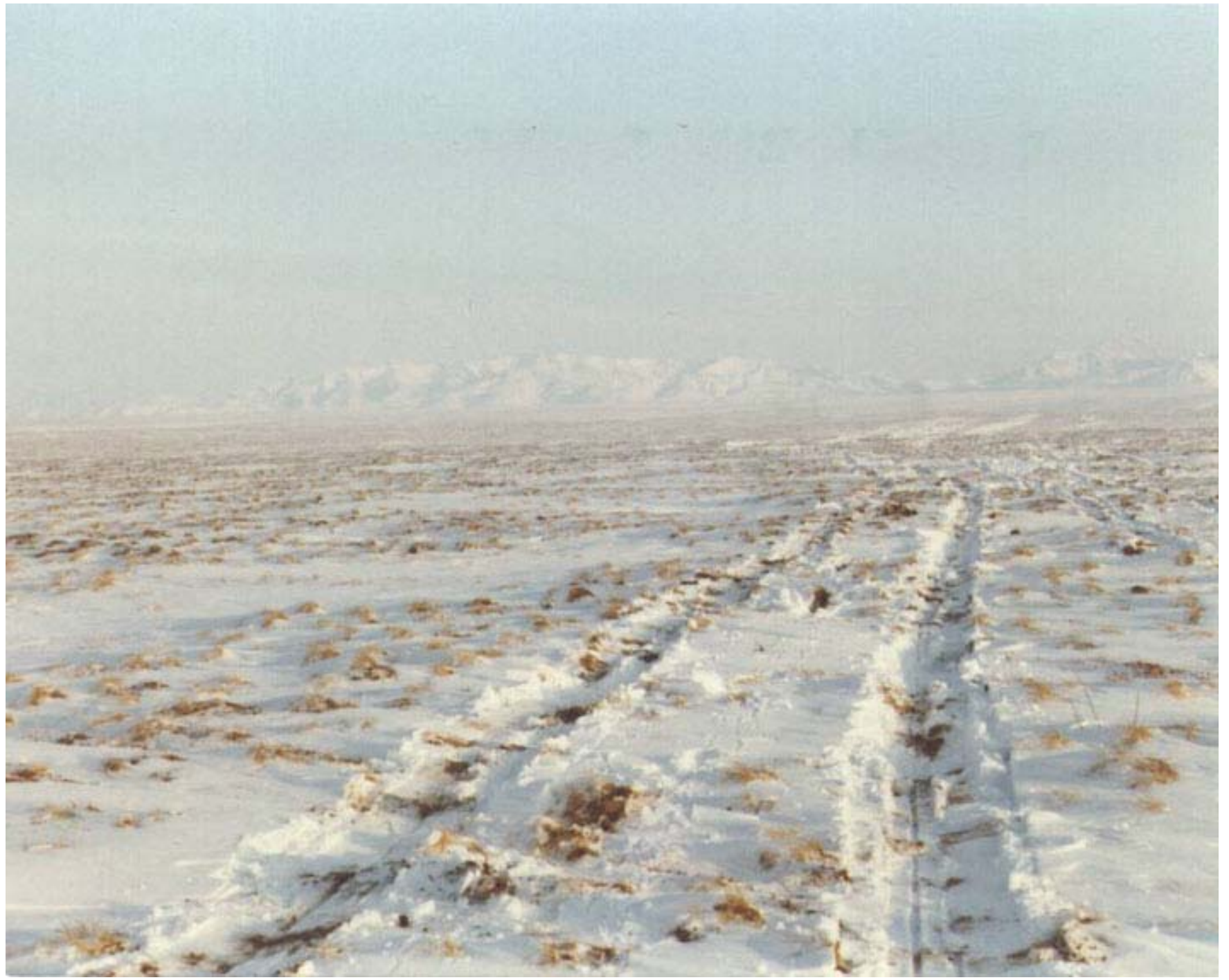

Pното E5. Camp-move trail on Tussock Tundra in April 1984. 


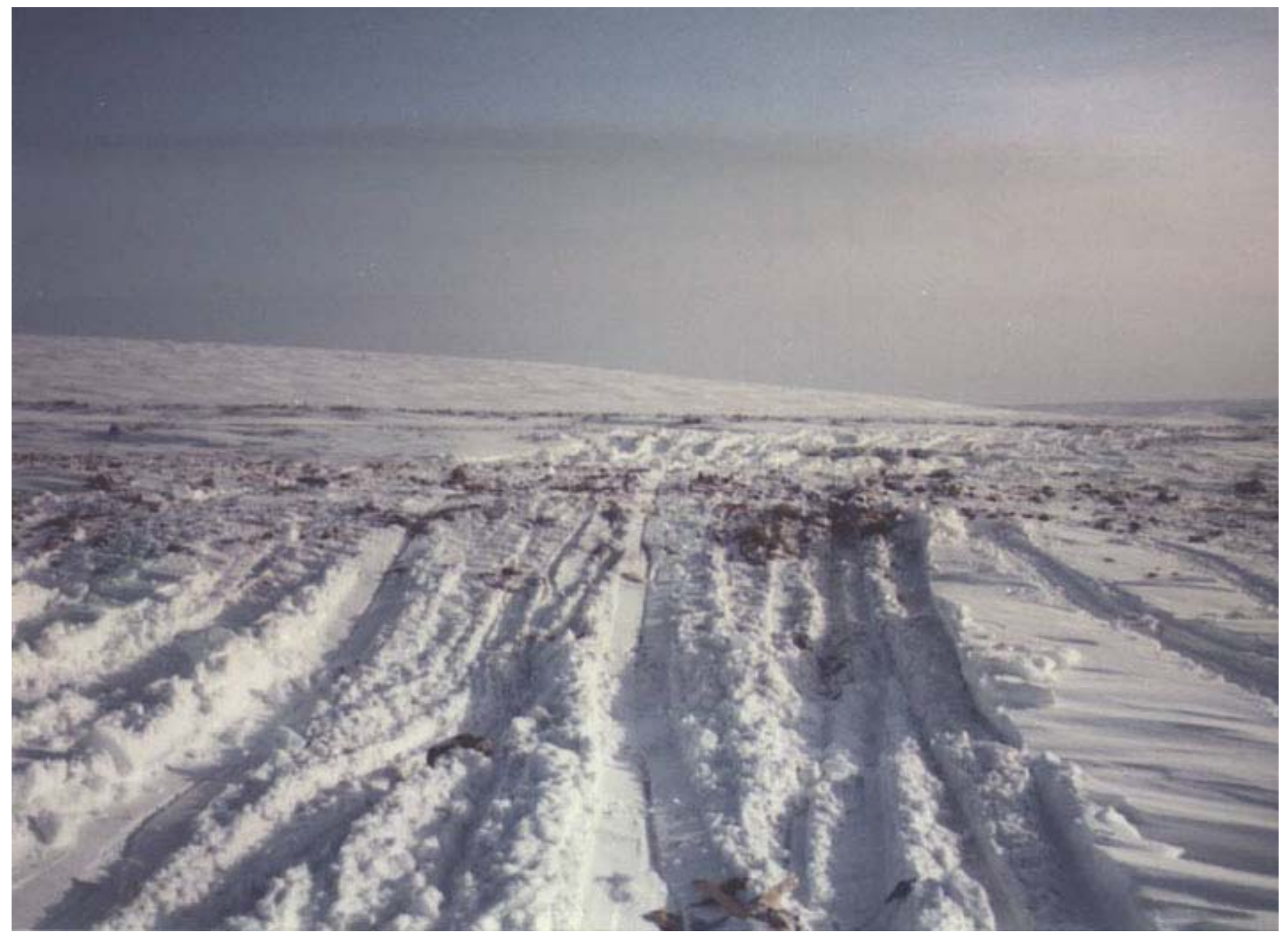

Pното E6. Trail photographed in March 1984 shows deep snow in swale in foreground and thin snow cover c area in background. 


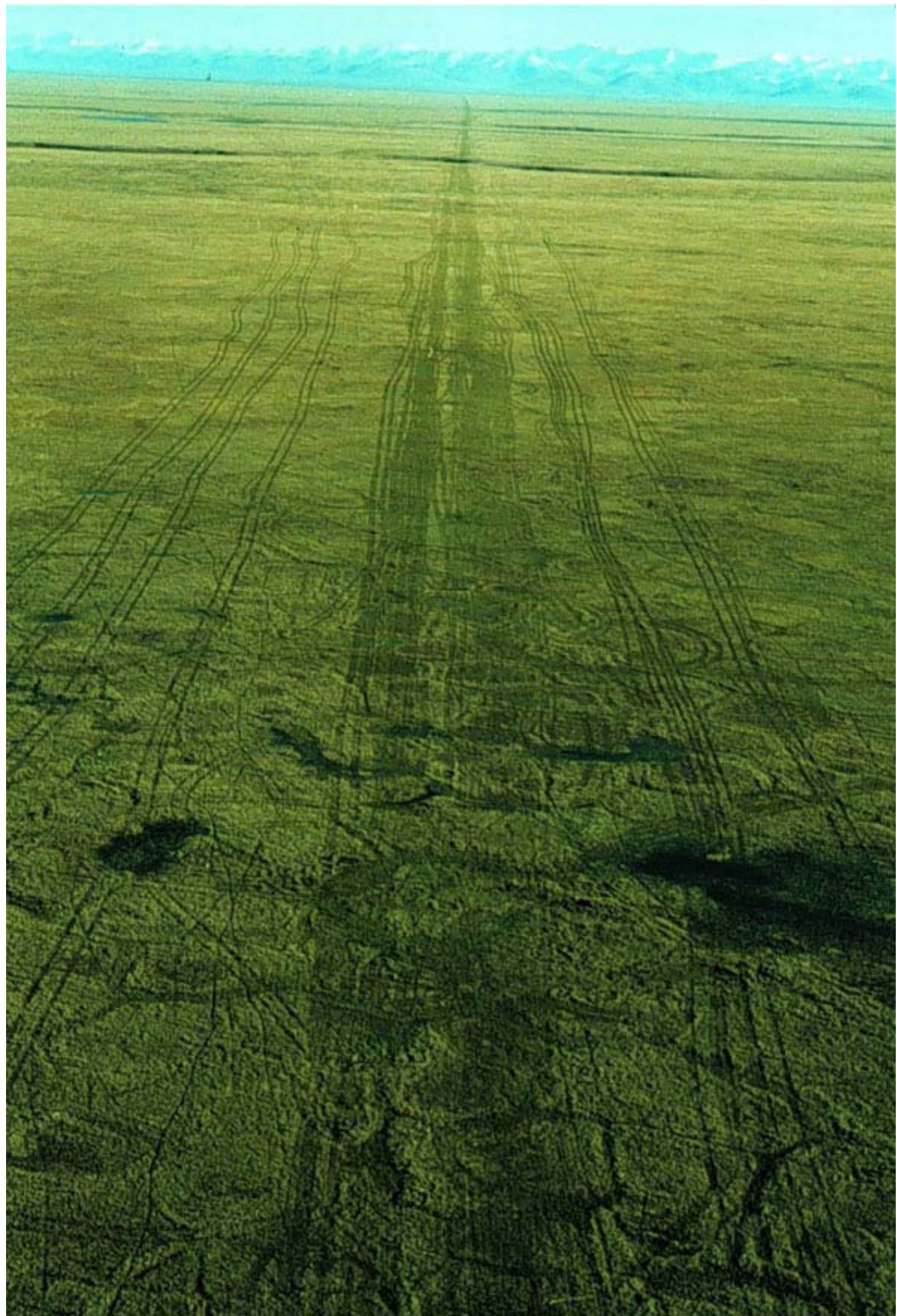

PHOTO E7. Aerial photograph of seismic line made in winter of 1985 on Sedge-Willow Tundra and photographed the following summer. The center of the trail is the survey line, the heavy tracks to either side are from vibrator units and recording vehicles, and the side trails are from single passes of smaller personnel vehicles. 


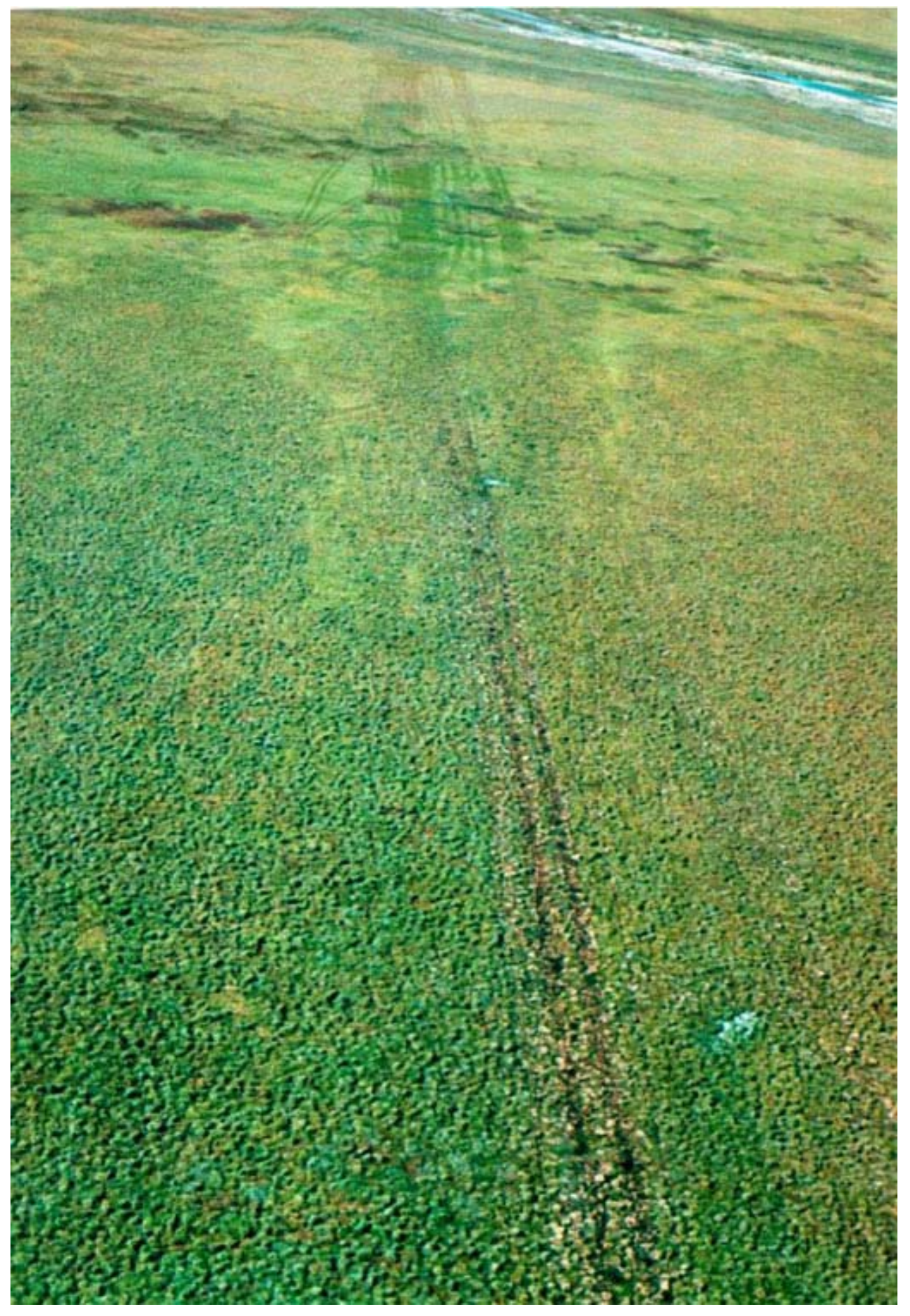

Pното E8. Aerial photograph of seismic line and overlapping camp-move trail made in winter of 1984, photographed in July 1984. Ruts in tussock tundra subsided into a trough. In 2002, tussocks were growing back, but trail still had only $5 \%$ cover of evergreen shrubs, compared to $30 \%$ in the surrounding tundra. 


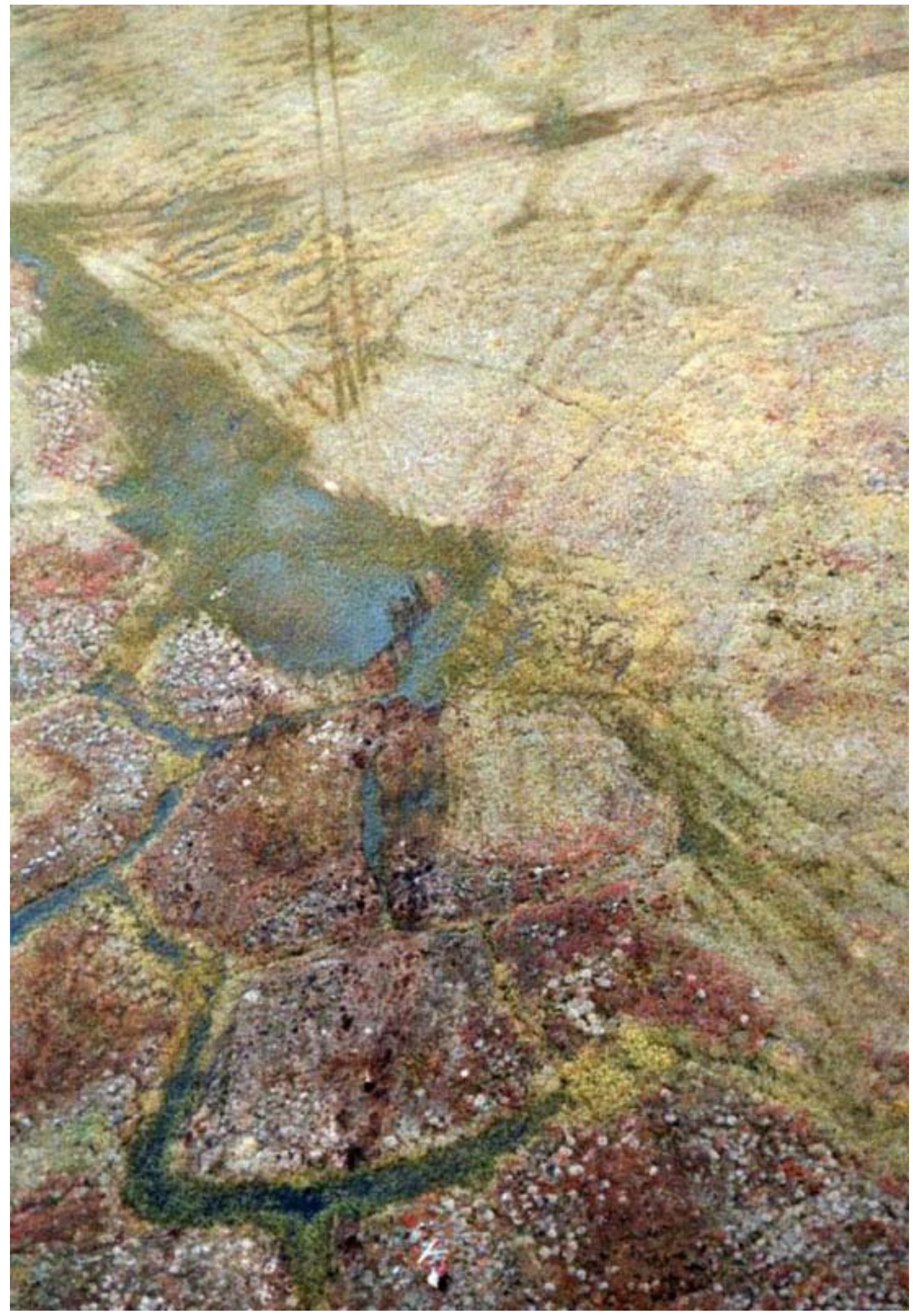

Pното E9. Aerial photograph in summer 1984 of tracks made by vehicles the previous winter. Scraped soil hummocks are visible in foreground and prominent, but shorter-lived "green trail effect" in background. Polygonal pattern is natural and is due to vertical ice wedges under the troughs between polygons. 


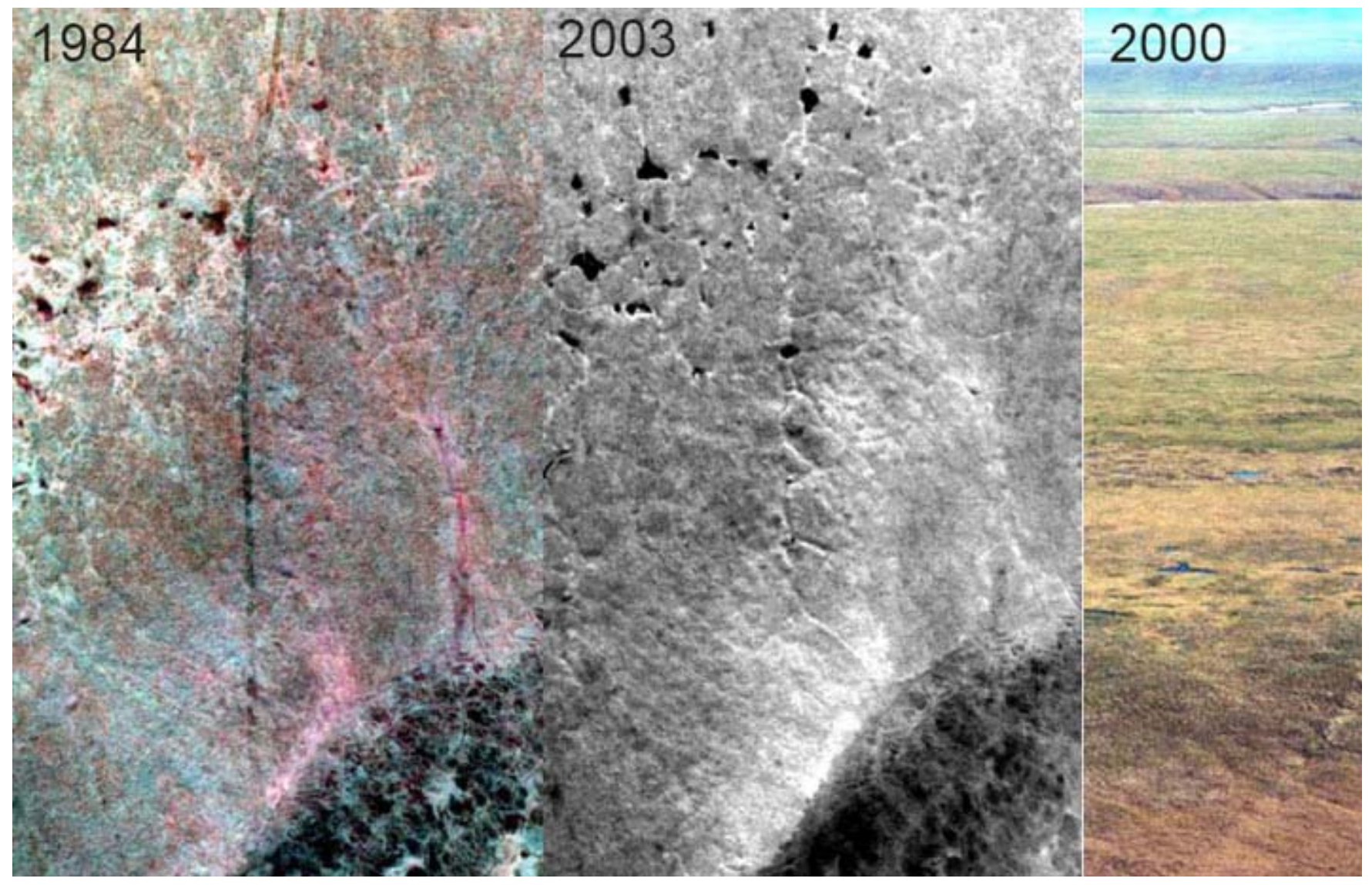

Pното E10. Highly disturbed trail on Sedge-Dryas Tundra, created by camp move vehicles in January 1984. 1 photograph taken in August 1984 (above) shows trail as dark line, due to increased bare soil on trail. Photo spar east-west. Quickbird satellite image from August 2003 (middle, same scale) and photograph from airplane from show troughs and two ponds that formed on trail when buried ice-wedges melted. Note general increase in patte amount of water in ponds between 1984 and 2003, probably due to warming climate. However, zig-zag shaped were up to $1 \mathrm{~m}$ deep and no similar feature was seen off the trail 

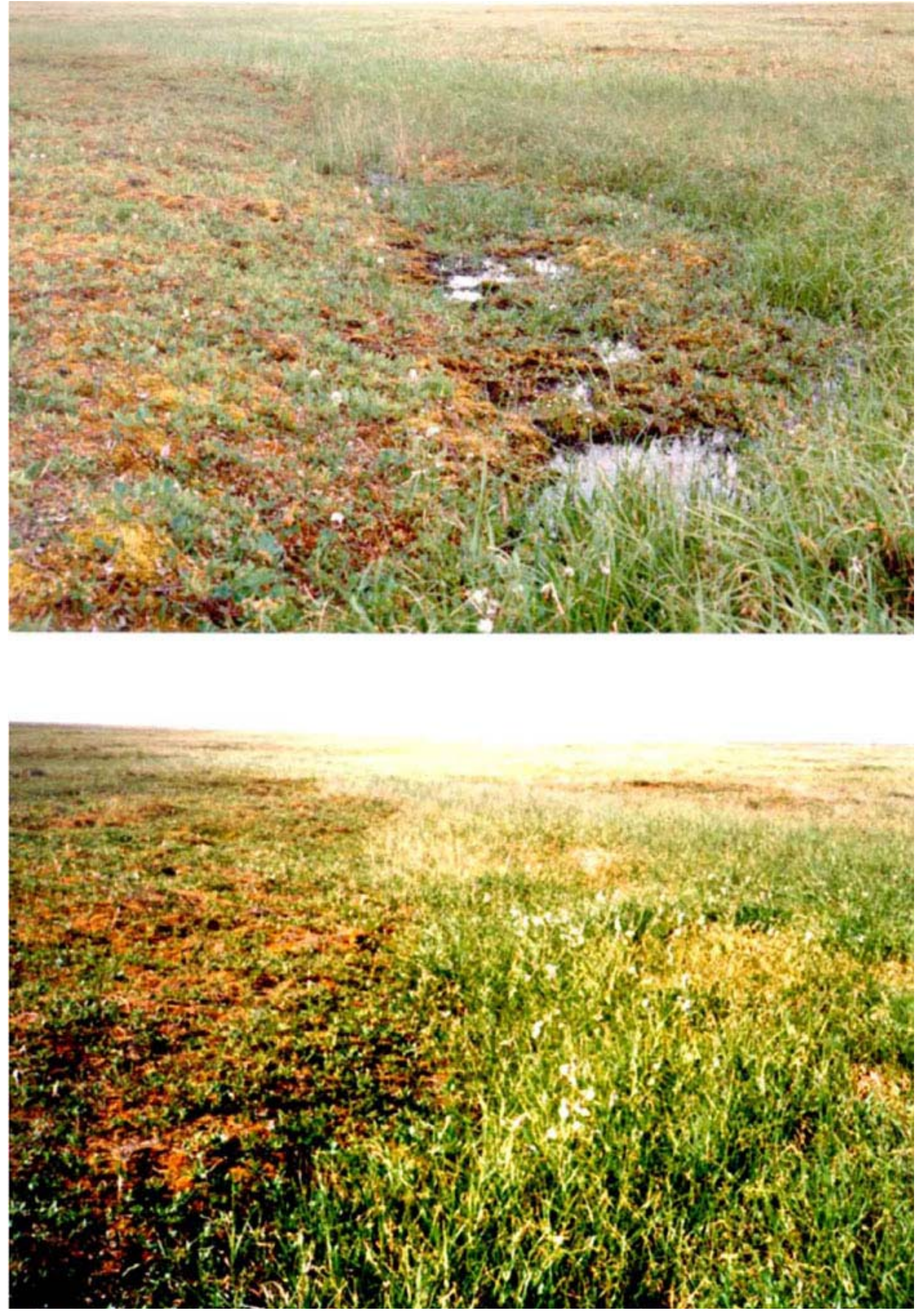
Рното E11. Repeat photographs of seismic trail across a raised area with dwarf shrubs and moss, with natural trough on right. 1989 photograph (top) shows collapse of the edge of the raised area into the adjacent trough after vehicle traffic during 1985 exploration. 1993 photograph (bottom) shows the same location after sedges had replaced the shrubs and mosses due to the altered moisture regime. 